\title{
Parametric Experiments on A Miniature Loop Heat Pipe with PTFE Wicks
}

\author{
Masahito NISHIKAWARA *1 and Hosei NAGANO* \\ * Nagoya Univ. Dept. of Aerospace Engineering \\ Furo-cho, Chikusa-ku, Nagoya, Aichi, 464-8603 Japan \\ ${ }^{1}$ E-mail: nishikawara@prop2.nuae.nagoya-u.ac.jp \\ ${ }^{1}$ Tel: +81-52-789-4405
}

\begin{abstract}
A miniature loop heat pipe (LHP) with polytetrafluoroethylene (PTFE) wicks was fabricated and its evaporator thermal performance was investigated with parametric experiments. The variables considered were the clearance between the cylindrical evaporator casing and the wick, the working fluid inventory, the properties of the working fluids, and the sink temperature. Micro-gaps between the outer surface of the wick and inner surface of the evaporator casing were included in the experiments with variables of clearance to investigate their effect on the evaporator heat-transfer coefficient. Ethanol, acetone, and R134a were charged in the LHP to evaluate the effect of the properties of the working fluids. The LHP tests were conducted with several $\mathrm{W} / \mathrm{cm}^{2}$ of applied heat flux to the evaporator under controlled sink temperature. The clearance seriously affected the evaporator heat-transfer coefficient, with a gap of 20 $\mu \mathrm{m}$ between the wick and casing having the best effect on the evaporator heat transfer across a range of tested heat fluxes. The effects of the working fluid inventory and fluid properties on the evaporator heat transfer were also clarified. Finally, the developed LHP was tested using ethanol as a working fluid under a stepwise heat load and sink temperature.
\end{abstract}

Key Words : Heat-Transfer Coefficient; Loop Heat Pipe; Porous Media; PTFE; Vapor-Liquid Two-Phase Flow

\section{Introduction}

Loop heat pipes (LHPs) are becoming standard thermal control devices for several thermally challenging space missions. The LHP has several advantages - i.e., it has no power requirement, a high heat-transfer capability, and a flexible framework, since it utilizes a capillary evaporator, heat transport of a phase change between liquid and vapor, and simple circular pipes as transport lines from the heat source to the radiator, respectively (Fig.1). One of the problems with the LHP miniaturization is the decrease in the heat-transfer coefficient due to the application of high heat flux and high flow resistance in the loop. In our work, polytetrafluoroethylene (PTFE) wicks, which have a bulk thermal conductivity of $0.25 \mathrm{~W} / \mathrm{m} \cdot \mathrm{K}$, were applied in an attempt to decrease heat leak (parasitic heat) from the evaporator to the compensation chamber (CC) and enhance the condenser heat-transfer coefficient by promoting the homogenization of radiator temperature [1].

Since the use of a wick with lower thermal conductivity decreases the heat leak to the CC, more of the heat load is transferred by evaporation, and the two-phase region in the condenser is increased, resulting in a high heat-transfer coefficient. On the other hand, a wick with lower thermal conductivity has a negative effect on the evaporator heat-transfer coefficient. The evaporator heat-transfer coefficient is defined as the temperature difference between the heating surface on the casing and the saturated vapor generated near the contact surface between the casing and the wick. It is considered that, in the evaporator heat-transfer coefficient, the thermal conduction of the porous media from the contact surface to the liquid-vapor interface in the wick is dominant. Therefore, a wick with lower thermal conductivity is less effective for enhancing the evaporator heat-transfer coefficient. Additionally, the heat leak to the CC through the evaporator casing increases due to reduction of the evaporator heat-transfer coefficient. For the reasons mentioned above, the effectiveness of a low thermal conductivity wick can be discussed in terms of the trade-off between increasing the condenser heat-transfer coefficient and decreasing the evaporator heat-transfer coefficient. This trade-off has been discussed and formulated in Ref. [2], which is 
based on an LHP steady-state model [3]. Also in Ref. [2], the applicable limits of the wick with low thermal conductivity on the LHP operating temperature were clarified.

\begin{tabular}{|c|c|}
\hline $\begin{array}{l}A \\
c_{p} \\
D \\
d P /\left.d T\right|_{\text {cat }} \\
h \\
h_{\text {lat }} \\
k \\
L \\
\dot{m} \\
N u \\
P \\
\dot{Q}_{\text {apply }} \\
\dot{Q}_{\text {case }} \\
\dot{Q}_{\text {evap }} \\
\dot{Q}_{\text {wick }} \\
R \\
r \\
T \\
V \\
\delta_{\text {gap }} \\
\varepsilon \\
v \\
\sigma \\
\text { subscripts } \\
\text { ave } \\
\text { cond } \\
\text { cont } \\
\text { cc } \\
\text { evap } \\
\text { eff } \\
i \\
l \\
o \\
\text { sat } \\
\text { sup } \\
\text { vp }\end{array}$ & $\begin{array}{l}\text { area } \mathrm{m}^{2} \\
\text { specific heat at constant pressure } \mathrm{J} / \mathrm{kg} \cdot \mathrm{K} \\
\text { diameter } \mathrm{m} \\
\text { gradient of saturation curve } \mathrm{Pa} / \mathrm{K} \\
\text { heat transfer coefficient } \mathrm{W} / \mathrm{m}^{2} \cdot \mathrm{K} \\
\text { latent heat } \mathrm{J} / \mathrm{kg} \\
\text { thermal conductivity } \mathrm{W} / \mathrm{m} \cdot \mathrm{K} \\
\text { length } \mathrm{m} \\
\text { mass flow rate } \mathrm{kg} / \mathrm{s} \\
\text { Nusselt number } \\
\text { pressure Pa } \\
\text { Heat applied to the evaporator } \mathrm{W} \\
\text { Heat leak to the } \mathrm{CC} \text { through the casing } \mathrm{W} \\
\text { Heat transferred by evaporation } \mathrm{W} \\
\text { Heat leak to the } \mathrm{CC} \text { through the wick } \mathrm{W} \\
\text { thermal resistance } \mathrm{K} / \mathrm{W} \\
\text { radius } \mathrm{m} \\
\text { temperature }{ }^{\circ} \mathrm{C} \\
\text { volume } \\
\text { gap distance } \mathrm{m} \\
\text { porosity } \\
\text { kinetic viscosity } \mathrm{m}^{2} / \mathrm{s} \\
\text { surface tension } \mathrm{N} / \mathrm{m}^{2} \\
\text { average } \\
\text { condenser } \\
\text { contact } \\
\text { compensation chamber } \\
\text { evaporation } \\
\text { effective } \\
\text { inner } \\
\text { liquid } \\
\text { outer } \\
\text { saturation } \\
\text { superheat } \\
\text { vapor pocket } \\
\text { a }\end{array}$ \\
\hline
\end{tabular}

Several studies have been conducted on LHPs with wicks of low thermal conductivity [1, 4 - 7]. PTFE, silicon oxide, iron oxide, UHMW polyethylene, and polyethylene have been used as the porous media. Nagano et al. [1], Riehl et al. [4], d'Entremont et al. [5], and J. H. Boo et al. [6] evaluated the operating temperature and the maximum amount of heat transport 
experimentally, using low thermal conductivity wicks. As mentioned in the previous paragraph, to argue the effectiveness of a low thermal conductivity wick, it is necessary to evaluate the evaporator heat-transfer coefficient. Kobayashi et al. [7] and Figus et al. [8] investigated the evaporator heat-transfer coefficient, but considered only the effects of heat flux or heat load dependence on the evaporator heat-transfer coefficient. Little attention has been paid to the effects of the clearance between the wick and the casing, the fluid properties, or the working fluid inventory on the evaporator heat-transfer coefficient of the LHP with a wick of low thermal conductivity.

The interface meniscus behavior in a porous structure of LHPs and capillary pumped loops (CPLs) has been researched [9 - 11]. When the heat flux applied to the capillary evaporator exceeds a certain value, a vapor pocket is created in the wick, as depicted in Fig. 2(a), which corresponds to the area surrounded by the dashed line in Fig.1. Lowering the heat-transfer coefficient of the evaporator, which is defined as the heat exchange between a heating surface and saturated vapor, is more less favorable when the thermal conductivity of the wick is lower. Additionally, such a two-phase wick increases the loss of pressure in the wick, because the kinetic viscosity of the vapor is higher than that of a liquid. To enhance the heat-transfer coefficient and capillary limit, it is necessary to prevent the liquid-vapor interface from receding. The dominant factor affecting the size of the vapor pocket area is the permeability of porous media near the contact surface between the wick and the heating surface. The conditions promoting the easy flow of vapor into the groove have been investigated. For example, a biporous structure wick [12], a two-layer cylindrical wick in which the outer wick has higher permeability [13], and circumferential grooves on the wick outer diameter and microgrooves on the evaporator inner diameter [4] have been proposed and evaluated. In this work, a gap between the wick and the evaporator casing, which was initially proposed by Figus [14], is introduced and investigated experimentally. We think that the gap is the simplest of the above approaches and could be easily applied. The concept of the gap effect is depicted in Fig. 2(b). The gap can be regarded as a porous structure that has the highest permeability of any porous media. Therefore, it helps to limit the creation of vapor pockets. However, on the heat-transfer coefficient, the gap must be equivalent to the thermal resistance. Judging from the above, the gap effect can be discussed in terms of the trade-off between decreasing the size of the vapor pocket in the wick and increasing the thermal resistance of the gap.

In a previous study [10], it was argued that eradication of the gap would be more beneficial for LHP operation. More precisely, at low heat loads with a saturated wick, the gap is unfavorable for the heat-transfer because the surface evaporation at the wick-groove interface is prevalent. However, we considered that characteristics of the heat-transfer would be dependent on the thermal conductivity of the wick and the size of the evaporator. In a miniature LHP, the heat flux is high, so the transition from a saturated wick to a liquid-vapor wick can take place even under a low heat load. As mentioned in the previous paragraph, once the liquid-vapor interface recedes with a low thermal conductivity wick, the lowering of the heat-transfer coefficient is more serious because the thermal conductivity is much lower than that of the metal wick. For example, there is a 64-fold difference between stainless steel and PTEF. This relation, i.e., the influence of wick thermal conductivity on the casing superheat, was examined numerically in a previous study [9]. It should be noted that the gap effect on boiling incipience was not a topic of this paper, but has also been treated previously [15].

This paper focuses on the experimental evaluation of the heat-transfer coefficient of LHP evaporators with a low thermal conductivity, as well as on the effect of the gap on the heat-transfer coefficient. To investigate the effects of the clearance between the wick and evaporator casing, the properties of the working fluid, and the fluid inventory on the evaporator heat-transfer coefficient, a miniature LHP with PTFE wicks was fabricated and parametric studies were performed. To enhance the evaporator heat-transfer coefficient, a gap was introduced between the wick and the evaporator casing and was investigated experimentally. Gap experiments were performed in the parametric studies to investigate the clearance between the wick and evaporator casing. Finally, the developed LHP was subjected to thermal performance tests using ethanol as a working fluid under a stepwise heat load and sink temperature.

\section{Experimental Apparatus}

\subsection{Fabrication of evaporators}


PTFE, which has a bulk thermal conductivity of $0.25 \mathrm{~W} / \mathrm{m} \cdot \mathrm{K}$, was used as the wick material to reduce heat leak across the wick. The PTFE wicks are shown in Fig. 3. The wicks were machined with a turning machine to form the inner core and outer surface, and then the vapor grooves were formed by an end mill. Several wicks with different casing diameters of up to $10.00 \mathrm{~mm}$ were fabricated to investigate the effect of the clearance between the wick and the evaporator casing on the evaporator heat-transfer coefficient. A seamless, stainless steel pipe was used as the evaporator casing. Table 1 lists the radius differences between the wick and the casing on each wick. Six evaporators with different wick diameters were developed: the differences between the wick diameter and the casing diameter were $-50,0,20,50,100$, and $500 \mu \mathrm{m}$. These values are the average measurement results of the difference in radius between the casing and the wick at room temperature. The variation all along the evaporator was $\pm 1 \mu \mathrm{m}$. A positive difference means that the casing inner diameter was larger than the wick outer diameter, and was equal to the gap distance. During the operation, the wick temperature increases and the wick diameter can enlarge due to the thermal expansion of the PTFE bulk in the porous structure. To investigate the effect of the thermal expansion on the gap distance, the diameter of the PTFE wick in the range from room temperature to $100{ }^{\circ} \mathrm{C}$ was measured with a constant-temperature oven. The expansion of the diameter was much small. It was confirmed that the effect on the gap distance was negligible. The porosity of the wick would have decreased to accommodate the expanded PTFE bulk when the wick temperature increased. Assuming the wick diameter do not change due to thermal expansion, relation between thermal expansion of bulk and change of the porosity is expressed as follows:

$$
\left(1-\varepsilon_{2}\right)-\left(1-\varepsilon_{1}\right)=\beta\left(1-\varepsilon_{1}\right) \Delta T
$$

where, $\varepsilon_{1}$ is porosity at room temperature, $\varepsilon_{2}$ is porosity at higher temperature, $\beta$ is coefficient of volume expansion, and $\Delta T$ is temperature difference. When the temperature difference is $80^{\circ} \mathrm{C}$ and coefficient of thermal expansion of PTFE is $10 \times 10^{-5}$ $/{ }^{\circ} \mathrm{C}$, the porosity decreases by $5 \%$ at most. Therefore, it is considered that this porosity decreasing cannot make a large impact on the evaporator performance. A negative gap means that a wick of larger diameter was forcibly installed into a casing of smaller diameter. In order to directly seal-off the vapor flow from the grooves to the CC, the diameter of the wick that was placed on the $\mathrm{CC}$ side, i.e., the part without grooves, was made $0.10 \mathrm{~mm}$ larger than the inner diameter of the evaporator casing. After the wick was installed into the casing, it was confirmed that no vapor could leak through the sealed portion of the evaporator by means of a measurement instrument that employs the bubble point method [16] and that was developed in our laboratory. The ratio of the area of the contact between the wick and the casing to the area of the inner side of the casing was 0.75 . The applied heat flux was $1.1 \mathrm{~W} / \mathrm{cm}^{2}$ at a heat load of $10 \mathrm{~W}$.

Table 2 lists the porous characteristics of the PTFE. The permeability and maximum pore radius were measured by using the instrument mentioned in the previous paragraph. First, the permeability was measured by the pressure difference between a porous sample and the flow rate of liquid ethanol in this instrument. Secondly, the bubble point pressure was measured by pressing nitrogen gas into the saturated porous sample. The contact angle between PTFE and ethanol was about $30^{\circ}$, which was measured by using a contact angle meter (KYOWA DM-301). The mode pore radius was measured by the mercury intrusion technique [17].

\subsection{Miniature LHP and measurement systems}

Table 3 lists the main characteristics of the experimental LHP. Table 4 lists the internal volume of each component and the fluid inventory in the loop at atmospheric temperature. $V_{c c}$ is the total internal volume of the CC and core of the wick, $V_{\text {wick }}$ is the void volume of the wick, $V_{\text {lines }}$ is the total internal volume of the grooves, vaporline, condenser, liquid line, and bayonet tube, and $V_{\text {charge }}$ is the fluid inventory in Table 4. $V_{\text {charge }}$ is set as more than the sum of $V_{\text {wick }}$ and $V_{\text {lines }}$ to avoid deprime and to allow continuous liquid accumulation in the $\mathrm{CC}$. The relation of fluid inventory to the CC internal volume affects the fluid distribution in the condenser and the CC during the operation, which controls the LHP thermal conductance. To investigate the effect of this relation on the thermal performance, LHP tests, in which the fluid inventory is variable, were conducted with fluid inventories of $13.0,15.5$, and $18.0 \mathrm{ml}$. The inventory ratio was defined as the ratio of the fluid inventory volume to the sum of the $\mathrm{CC}$ internal volume and void volume of the wick, as follows: 
The inventory ratios were $0.95,1.14$, and 1.32 , respectively. When the inventory ratio is less than 1 , vapor is always in the $\mathrm{CC}$ under any condition. An inventory ratio of 0.95 can be used to avoid hysteresis in connection with the formation of a vapor phase in the CC, as indicated experimentally by Vershinin et al. [18]. Three working fluids of ethanol, acetone, and R134a, each with good wettability to PTFE, were used to investigate the effects of the properties of the working fluid. The working fluid was charged after the LHP was back-filled less than $10^{-3} \mathrm{~Pa}$ by using the rotary and turbo molecular pumps.

Figure 4(a) shows a photograph of the experimental LHP, which was manufactured at our facilities. Figure 4(b) shows the arrangement of the PTFE wick, the bayonet tube, the heater block, and the evaporator casing. An aluminum heater block weighing $29 \mathrm{~g}$ and containing four cartridge heaters was attached to the evaporator. The condenser was mounted on an aluminum cold plate and a copper plate with a pipe for coolant. The copper plate was cooled by an ethylene glycol/water mixture from a chiller unit that was flowed through the pipe for sink temperature control. Because there was no secondary wick and the CC was situated above the evaporator, the LHP was tilted to vertical to supply liquid to the primary wick. During the test, the entire LHP was covered with thermal insulators. Before the fluid charging, heat loss from the evaporator unit to ambient air was estimated with insulation tests and expressed as a quadratic function of the temperature difference between the heater block and ambient air to accurately calculate the heat applied to the LHP, $\dot{Q}_{a p p l y}$, from the power input and the heat loss. Two absolute pressure sensors when the working fluids were ethanol and acetone or an absolute pressure sensor and a pressure difference sensor when the working fluid was R134a were located at the inlet of the vapor line and the outlet of the liquid line to measure the saturation temperature of the fluids. The LHP temperatures including ambient temperature were measured by 40 T-type thermocouples. Representative measurement locations are shown in Fig. 4(a) and (b).. The data acquisition and power supply units were an Agilent 34970A and 6644A, respectively. They were managed automatically by LabVIEW ${ }^{\mathrm{TM}}$ software on a personal computer. Data were acquired every 5 seconds. Tests were conducted twice under the same conditions to ensure the repeatability of results. If any thermocouple reached $100^{\circ} \mathrm{C}$, the heat load was stopped.

The saturation temperature was calculated from the measured pressure and saturation curve of the working fluid. Two calculated saturation temperatures at the inlet of the vapor line and the outlet of the liquid line almost corresponded to the saturation temperature in the grooves and the CC, respectively. The transferred heat by evaporation, $\dot{Q}_{\text {evap }}$, evaporation heat flux, $\dot{q}_{\text {evap }}$, heat-transfer coefficients of the evaporator and condenser, $h_{\text {evap }}$ and $h_{\text {cond }}$, and thermal resistances of the evaporator, condenser, and LHP, $R_{\text {evap }}$, and, $R_{\text {cond }}$, and, $R_{L H P}$, were calculated as follows:

$$
\begin{aligned}
& \dot{Q}_{\text {evap }}=\dot{Q}_{\text {apply }} /\left[1+c_{p_{-} l}\left(T_{l}-T_{\text {sat }(P v)}\right) / h_{\text {lat }}\right] \\
& \dot{q}_{\text {evap }}=\dot{Q}_{\text {evap }} / A_{\text {cont }} \\
& h_{\text {evap }}=\dot{Q}_{\text {evap }} /\left[\left(T_{e_{-} \text {ave }}-T_{\text {sat }(P v)}\right) A_{\text {cont }}\right] \\
& h_{\text {cond }}=\dot{Q}_{\text {evap }} /\left[\left(T_{\text {sat }(P v)}-T_{\text {cond }(2 f)}\right) \times \pi D_{\text {cond }}^{i} L_{2 f}\right] \\
& R_{\text {evap }}=\left(T_{\text {e_ave }}-T_{\text {sat }(P v)}\right) / \dot{Q}_{\text {apply }} \\
& R_{\text {cond }}=\left(T_{\text {sat }(P v)}-T_{\text {cond_ave }}\right) / \dot{Q}_{\text {apply }}
\end{aligned}
$$




$$
R_{L H P}=\left(T_{e \_a v e}-T_{\text {cond_ave }}\right) / \dot{Q}_{\text {apply }}
$$

Equation (3) is the energy conservation of the evaporator and the CC. Note that the heat flows in Eqs. (5) to (9) are different. The transferred heat by phase change was considered to be an accurate estimate of the heat-transfer coefficient of evaporation and condensation in Eqs. (5) and (6).

\section{Results and Discussion}

Table 5 lists the conditions used in each test.

\subsection{Effect of the contact between the wick and the evaporator casing (No. I in Table 5)}

LHP experiments with radius differences of -50, 0, 20, 50, 100, and $500 \mu \mathrm{m}$ between the evaporator casing and the wick were conducted to investigate the effect of the clearance on the evaporator heat-transfer coefficient. The working fluid was ethanol, and the sink temperature was set at $30^{\circ} \mathrm{C}$. Figure 5 shows the average temperatures of the evaporator casing (TC14, 17) and the CC wall (4 thermocouples) for each radius difference in a steady state. The LHP with a $500 \mu \mathrm{m}$ gap could not operate due to the overly large evaporator thermal resistance, and it reached the upper limit temperature as shown in Fig.6. It can be seen from Fig.5 that the temperature of the CC varied only slightly among the different radii. On the other hand, there were large temperature differences for the evaporator. The evaporator temperature at a heat load of $20 \mathrm{~W}$ was highest for the radius difference of $100 \mu \mathrm{m}$, followed in order by the radius differences of $50 \mu \mathrm{m},-50 \mu \mathrm{m}$, and $0 \mu \mathrm{m}$, with the lowest temperature being observed for the radius difference of $20 \mu \mathrm{m}$. It was thus clarified that the clearance between the evaporator casing and the wick had a large effect on the operating temperature.

Figure 7 presents the evaporator heat-transfer coefficient for each radius difference at an evaporation heat flux from 1.5 to $1.6 \mathrm{~W} / \mathrm{cm}^{2}$. It was found that the evaporator heat-transfer coefficient had a local maximum value when the gap between the wick and the evaporator casing was $20 \mu \mathrm{m}$. As a result, it is clear that the radius difference affects the characteristics of the evaporator heat-transfer quite directly. Let us consider the reason for the lower heat transfer coefficient of the evaporator having negative gaps. SEM pictures of the porous structure at the wick outer surface before and after installing the casing are shown in Fig. 8(a) and (b). The two pictures correspond to the outer surface of the positive and negative gap, respectively. Collapse of the porous structure can be seen in Fig. 8(b). The collapse was confined near the contact surface with the casing, and was not observed near the inner side. Under such a condition, the recession of the liquid-vapor interface will be further promoted. It is reasonable to suppose that the negative gaps in the low heat transfer coefficient of the evaporator were caused by the decrease of local permeability near the contact surface.

Next we consider the gap effect. The values of the evaporator heat-transfer coefficient at the 0 and $20 \mu \mathrm{m}$ gap were 1,500 and $1,900 \mathrm{~W} / \mathrm{m}^{2} \cdot \mathrm{K}$, respectively. It is considered that the interface recession toward the inner core was prevented at the $20 \mu \mathrm{m}$ gap. The results of these tests implied that the evaporator of the PTFE wick with an optimum gap has the most beneficial effect on the evaporator heat-transfer performance. Note that the gap may have a negative effect on the heat-transfer coefficient in some cases because it is possible that the effectiveness of the gap depends on the porous characteristics, thermal conductivity of the wick, and the LHP configuration. On the other hand, the reason why the heat transfer coefficient is low on the positive gap side may well be to increase the thermal resistance of vapor in the gap layer. Assuming the liquid-vapor interface is on the wick outer surface, as shown in Fig. 2(b), the Nusselt number of the gap can be calculated by using the heat-transfer coefficient, the thermal conductivity of vapor, and the gap distance as follows:

$$
N u_{\text {gap }}=h_{\text {evap }} /\left(k_{v} / \delta_{\text {gap }}\right)
$$

As a result of the calculation using the least-square method, the Nusselt number of the gap, $N u_{g a p}$, was 1.9. The dashed line in Fig. 7 shows the plot of Eq. (10) when $N u_{\text {gap }}$ is 1.9.

Figure 9 presents the temperature distribution of the evaporator casing for the axial direction at each gap. The thermocouple positions are shown in Fig. 4(b). The Y-axis represents the superheat, which is expressed as the temperature 
difference between the evaporator casing and saturated vapor in the grooves, which is calculated from the pressure measured at the inlet of the vapor line. TC14 was the highest temperature of all thermocouples at any gap distance. Because the temperature distribution on the casing corresponds to the vapor-liquid interface distribution in the wick, it is speculated that the interface is distributed in the axial-direction on the cylindrical evaporator, as well as in the circumferential direction. Based on the data in Fig. 9, the distribution variation for the $20 \mu \mathrm{m}$ gap was the smallest. Temperature homogenization in the axial direction was promoted by the vapor flow in the $20 \mu \mathrm{m}$ gap. This is why the evaporator with a gap of $20 \mu \mathrm{m}$ has the highest heat-transfer coefficient.

\subsection{Effect of the working fluid inventory (No. II in Table 5)}

LHP experiments using inventory ratios of $0.95,1.14$, and 1.32 were conducted to investigate the effect of the working fluid inventory. The working fluid was ethanol, the sink temperature was set at $30{ }^{\circ} \mathrm{C}$, and the gap distance was $20 \mu \mathrm{m}$. Figure 10 presents the average temperature of the evaporator casing (TC14, 17), the CC wall (4 thermocouples), and the condenser pipe (10 thermocouples), the saturation temperature in the grooves, the temperature at the outlet of the liquid line, and the pressure difference of the transport lines at a head load of $40 \mathrm{~W}$ for each inventory ratio in a steady state.

The evaporator temperature increases with increasing inventory ratio. The evaporator heat-transfer coefficient at each inventory ratio is presented in Fig. 11. The evaporator heat-transfer coefficient increases with increasing inventory ratio. One of the reasons for this relation may be that the pressure difference decreases as the inventory ratio increases. The results of the evaporator heat-transfer coefficient in Fig. 11 do not help to explain the increase of the evaporator temperature in Fig. 10. This is because the evaporator temperature should decrease if the evaporator heat-transfer coefficient increases as in Fig. 11. These facts imply that the reason for the increase in the evaporator temperature was heat transfer in the condenser. Figure 12 presents the temperature distribution of the condenser at each inventory ratio. Ten thermocouples were attached to the pipe at regular $55 \mathrm{~mm}$ intervals. The Y-axis represents the temperature difference in response to sink temperature. The temperature gradient in the two-phase region should be much smaller, because the heat is almost completely transferred by condensation. The two-phase region, which decreases as the inventory ratio increases, can be seen on the left side of Fig. 12. An increase in the inventory ratio can cause an increase in the single phase length in the condenser-in other words, a decrease in the two-phase length, which has a much higher heat-transfer coefficient. Additionally, the saturation temperature of vapor increases with decreasing area of the two-phase region. Therefore, it can be concluded that a decrease in the two-phase length leads to an increase of the evaporator temperature. From the results in Fig. 12, the condensation heat-transfer coefficient, $h_{\text {cond }}$, of ethanol in vertical upflow was about $1800-2100 \mathrm{~W} / \mathrm{m}^{2} \cdot \mathrm{K}$.

\subsection{Effect of the properties of the working fluids (No. III in Table 5)}

LHP experiments with ethanol, acetone, and R134a were conducted to investigate the effect of the properties of the working fluid. The sink temperature was set at $10^{\circ} \mathrm{C}$, and the gap distance was $0 \mu \mathrm{m}$. The sink temperature of $10^{\circ} \mathrm{C}$ was chosen to standardize the test conditions of the LHPs with the three working fluids at normal operations. The gap distance of $0 \mu \mathrm{m}$ was chosen to erase the gap effect from the results and to investigate the effect of the working fluid on the heat-transfer coefficient of the evaporator without gap. Figure 13 presents the evaporator temperature and pressure difference of transport lines on each working fluid. The maximum heat load was observed for acetone, followed in order by ethanol and R134a. Table 6 lists the main properties of each working fluid at $300 \mathrm{~K}$. The values of the figure of merit, $N_{f}$, were 316 (acetone), 148 (ethanol), and 86.9 (R134a) MW/m². This order agrees with the results for the maximum transported heat. The pressure difference of transport lines with R134a was the smallest of all. The pressure difference of vapor is much larger than that of liquid when the pipe diameter of the vaporline, the condenser, and the liquid line are the same. $h_{\text {lat }} / v_{v}$ is the property most related to the pressure loss of vapor, and the fluid with a high $h_{\text {lat }} / v_{v}$ has a low pressure loss of vapor. The $h_{\text {lat }} / v_{v}$ of R134a was the largest of all, as shown in Table 6, which agrees with the results of the smallest pressure difference. The highest evaporator temperature was observed for ethanol, followed by acetone and R134a. The temperatures at the outlet of the liquid line were not different. Therefore, the reason for the difference in evaporator temperature was not the effect of the returning liquid. The reason may have been the difference in the gradient of 
the saturation curve, as listed in Table 6. The order of the $d P /\left.d T\right|_{\text {sat }}$ value at $300 \mathrm{~K}$ agrees with the order of the results of the evaporator temperature. To generate the required pressure difference in the transport lines, the corresponding $d P /\left.d T\right|_{\text {sat }}$ is needed. If $d P /\left.d T\right|_{\text {sat }}$ is smaller than the corresponding value, the fluid seek to reach a high temperature state to find larger $d P /\left.d T\right|_{\text {sat }}$, because $d P /\left.d T\right|_{\text {sat }}$ increases monotonically against temperature.

Figure 14 presents the evaporator heat-transfer coefficient and the evaporation ratio, which is the ratio of transferred heat by evaporation to the heat load, on each working fluid. The heat-transfer coefficient of R134a is highest, except when the heat flux is the highest. This high heat transfer was caused by the lower pressure loss of vapor in the wick. This prevented the liquid-vapor interface from receding, and created the higher heat-transfer coefficient in the evaporator. As mentioned above, the $h_{\text {lat }} / v_{v}$ of R134a was largest, and therefore, the pressure loss of vapor in the wick with R134a was the smallest. However, at a higher heat flux, due to the recession of the vapor-liquid interface, the evaporator heat-transfer coefficient could be lower. The evaporation ratio with R134a was the highest, as shown in Fig.14. Because the gradient of the saturation curve, $d P /\left.d T\right|_{\text {sat }}$ of R134a was higher than that of the other fluids, the temperature difference between the evaporator and the $\mathrm{CC}$ was smaller, which led to the low heat leak across the wick. As a result, the evaporation ratio was the highest.

\subsection{Heat load and sink tests (No. IV and V in Table 5)}

LHP experiments under a stepwise heat load were conducted to evaluate the thermal performance of the LHP. The sink temperature was set at $30^{\circ} \mathrm{C}$, the working fluid was ethanol, and the gap distance was $20 \mu \mathrm{m}$. Figures 15 and 16 present the effects of temperature on each component and the pressure difference of transport lines across time. In the other test, to investigate the maximum heat load, the evaporator temperature was over the upper limit when the heat load was $45 \mathrm{~W}$. Therefore, in this test, the maximum heat load was set at $40 \mathrm{~W}$. The start-up of LHP was 100 seconds after the heat was loaded. At the moment of the start-up, no noticeable superheat was observed, as can be seen in the scale-up figure in the upper left of Fig. 15. Unstable behavior of the pressure difference after the start-up does not have a significant effect on temperature, and therefore, it is not a problem for the LHP operation. The operation was stable after 900 seconds at the first step of $10 \mathrm{~W}$. At the other step, the relaxation time was around 150 seconds. Hysteresis of the evaporation temperature was observed at $30 \mathrm{~W}$ of heat loads. The temperature difference was $2^{\circ} \mathrm{C}$ and was caused by hysteresis connected with the heat exchange in the evaporation zone that was described by Vershinin et al. [18]. The evaporator heat-transfer coefficients were 2,400 and $2,000 \mathrm{~W} / \mathrm{m}^{2} \cdot \mathrm{K}$, respectively. The pressure oscillation occurred at the lowest heat load of $5 \mathrm{~W}$. The period of the oscillation was 115 seconds. There are several possible reasons for the oscillation. Three types of oscillation behavior of the LHP were reported in previous studies [19-21]. The first is caused by a lack of fluid inventory. The second is caused by a large thermal mass attached to the evaporator. The third occurs when the vapor front is near the inlet or the outlet of the condenser. In the present work, since the fluid inventory was sufficient to supply liquid to the wick at any time, the reason must not have been an insufficient amount of working fluid as discussed in Ref. [19]. Since the heat capacity of the aluminum thermal mass applying heat load to the evaporator casing was small, the reason was also not a large thermal mass as presented in Ref. [20]. Temperature oscillation was observed at the inlet of the condenser. Therefore, the observed oscillation was of the third type, as presented in Ref. [21], which occurs when the vapor front is near the inlet or the outlet of the condenser. However, we considered that the cause was different from that of Ref. [21]. The reason may have been the reverse flow induced by boiling in the CC, since the temperature at the outlet of the liquid line had oscillated. The amplitude of the oscillation at the outlet of the liquid line was $1.8^{\circ} \mathrm{C}$. Let us consider the above speculation in relation to the estimation of the liquid superheat in the core of wick. The core temperature, $T_{\text {core }}$, which is defined as the inner temperature of the wick, is estimated with heat leak across the wick, $\dot{Q}_{\text {wick }}$ as follows:

$$
\begin{aligned}
& T_{\text {core }}=T_{\text {sat }}-\dot{Q}_{\text {wick }} \cdot R_{\text {wick }} \\
& \dot{Q}_{\text {wick }}=\dot{Q}_{\text {apply }}-\left(\dot{Q}_{\text {evap }}+\dot{Q}_{\text {case }}\right)
\end{aligned}
$$




$$
R_{\text {wick }}=\frac{1-\left(r_{\text {wick }}^{o} / r_{\text {wick }}^{i}\right)^{-\left(\dot{m} c_{p_{-} l} / 2 \pi k_{\text {wick }} \text { eff } L_{\text {wick }}\right)}}{\dot{m} c_{p_{-} l}}
$$

Here, Eq. (12) presents the energy distribution of the heat load, and the heat leak through the casing, and $\dot{Q}_{\text {case }}$ is calculated with the thermal resistance of the stainless casing on the evaporator and the CC. Equation (13) is the thermal resistance of the cylinder wick considering the convection effect, which is an analytical solution with assumption of 1D flow in the radial direction. The effective thermal conductivity of the wick, $k_{\text {wick_eff }}$, is calculated by parallel law as follows:

$$
k_{\text {wick_eff }}=\varepsilon k_{l}+(1-\varepsilon) k_{P T F E}
$$

where $k_{l}$ is 0.15 and $k_{\text {PTFE }}$ is $0.25 \mathrm{~W} / \mathrm{m} \cdot \mathrm{K}$.

Figure 17 presents the calculation results for the temperature in the wick core. The Y-axis represents the superheat, which is the temperature difference between the core and saturation in the CC. At the lowest heat load, the superheat value is $5.9^{\circ} \mathrm{C}$ at the maximum, and therefore the results imply that boiling in the wick core could be possible. The heat leak from the evaporator to the $\mathrm{CC}$ is larger at lower heat loads because thermal resistance to the sink is large when the two-phase length in the condenser is short. Such a situation may lead to superheated liquid in the core, as shown in Fig. $17 . \quad$ Above a certain superheat, vapor bubbles are generated in the core, and the volume expansion induces reverse flow. The generation of the vapor bubbles could be repeated periodically, which would cause the pressure and temperature oscillation. The superheat values were $5.9^{\circ} \mathrm{C}$ and $4.7^{\circ} \mathrm{C}$ at the highest and lowest amplitudes.

LHP experiments under stepwise sink temperature were conducted to evaluate the thermal performance of the LHP. The heat load was set at $30 \mathrm{~W}$, the working fluid was ethanol, and the gap distance was $20 \mu \mathrm{m}$. Figures 18 and 19 present the time history of temperature on each component and pressure difference of transport lines. The interval of the stepwise sink temperature was $15^{\circ} \mathrm{C}$, and the minimum and maximum values were $0^{\circ} \mathrm{C}$ and $75^{\circ} \mathrm{C}$, respectively. The evaporator temperature was almost constant with a sink temperature of less than $45^{\circ} \mathrm{C}$. This means that the operation mode is variable conductance in the condenser. Right after the sink temperature increased to $60^{\circ} \mathrm{C}$, the temperature at the outlet of the liquid line, $T_{l}$, increased rapidly. This result shows that the vapor penetrated the condenser, and reached the outlet of the liquid line. However, dryout did not occur, and the LHP continued its stable operation. This LHP showed highly reliable operation in the case of a heat sink with high temperature. The thermal resistance of the evaporator, the condenser, and the total of the LHP are shown in Fig. 20. The thermal resistance of the condenser, $R_{\text {cond }}$, was little changed at a sink temperature of more than $45^{\circ} \mathrm{C}$. This behavior was evidence of the boundary between the variable and constant conductance mode of the LHP operation. The values of $R_{\text {evap }}, R_{\text {cond }}$, and $R_{L H P}$ were lowest at the highest sink temperature of $75^{\circ} \mathrm{C}$, i.e., $0.25,0.057$, and $0.30 \mathrm{~K} / \mathrm{W}$, respectively.

\section{Conclusion}

In this paper, a miniature LHP with PTFE wicks was fabricated and a parametric study was performed to investigate the effect of clearance between the wick and evaporator casing, the properties of working fluid, and the fluid inventory on the evaporator heat-transfer coefficient. The gap between the wick and the evaporator casing was introduced and investigated experimentally to enhance the evaporator heat-transfer coefficient with a wick of low thermal conductivity. The following were found.

i. It was clarified that the clearance between the evaporator casing and the wick had a large effect on the heat-transfer coefficient of the evaporator. When the gap was negative, i.e., when the wick outer diameter was larger than the casing inner diameter, the evaporator heat-transfer coefficient at the $0 \mu \mathrm{m}$ gap was higher than that at the $-50 \mu \mathrm{m}$ gap. It was found that the evaporator heat-transfer coefficient at the $20 \mu \mathrm{m}$ gap was higher than that at the $0 \mu \mathrm{m}$ gap in this LHP configuration. 
ii. The evaporator temperature increased with increasing inventory ratio of the working fluid. This was caused by an increase in the thermal resistance of the condenser, not the evaporator. It can be concluded that a decrease of the two-phase length in the condenser due to excess fluid inventory leads to an increase of the evaporator temperature.

iii. The results of the LHP experiments with ethanol, acetone, and R134a revealed differences in the maximum transferred heat corresponding to the figure of merit of each working fluid. The results of the effect of fluid properties on the operating temperature, pressure difference, and evaporator heat-transfer coefficient were clarified.

iv. Finally, thermal performance tests of the developed LHP were performed using ethanol as a working fluid under a stepwise heat load and sink temperature. The LHP achieved a maximum heat load of $40 \mathrm{~W}$ and applied heat flux of 4 $\mathrm{W} / \mathrm{cm}^{2}$. Pressure and temperature oscillation were observed at the lowest heat load. Based on the estimation of temperature in the wick core, it was implied that the reason for the oscillations was the reverse flow induced by boiling in the wick core. The LHP could operate stably at the hottest sink temperature even when the vapor penetrated the condenser and flowed to the CC. The thermal resistance of the LHP was $0.30 \mathrm{~K} / \mathrm{W}$ at a heat load of $30 \mathrm{~W}$ and a sink temperature of $75^{\circ} \mathrm{C}$.

\section{Acknowledgements}

This research was partially supported by a Grant-in-Aid for JSPS Fellows (No. 25148) and by JST, PRESTO.

\section{References}

[1] H. Nagano, F. Fukuyoshi, H. Ogawa, H. Nagai, Development of an Experimental Small Loop Heat Pipe with Polytetrafluoroethylene Wicks, J. Thermophys. Heat Transf. 25 (2011) 547-552.

[2] M. Nishikawara, H. Nagano, Study on Evaporator Heat Transfer Characteristics of a Miniature Loop Heat Pipes with Low Thermal Conductivity Wicks, in: Proc. of the Third Int. Forum on Heat Transf., Nagasaki, Japan, 13-15 November 2012, No. IFHT2012-013.

[3] T. Kaya, T. T. Hoang, Mathematical Modeling of Loop Heat Pipes and Experimental Validation, J. Thermophys. Heat Transf., 13 (1999) 314-320.

[4] R. R. Riehl, N. dos Santos, Performance Improvement in Loop Heat Pipe Using Primary Wick with Circumferential Grooves, in: Proc. of 36th Int. Conference on Environmental Systems, Norfolk, Virginia, 27-20 July 2006, SAE Paper 2006-01-2172,.

[5] B. P. d'Entremont, J. M. Ochterbeck, Performance of Ceramic Wick Evaporators for Loop Heat Pipes and Capillary Pumped Loops, in: Proc. of 38th AIAA Thermophys. Conference, Toronto, Canada, 6-9 June 2005, AIAA Paper 2005-4955.

[6] J. H. Boo, W. B. Chung, Experimental study on the thermal performance of a small-scale loop heat pipe with polypropylene wick, J. Mechanical Sci. Technol., 19 (2005) 1052-1061.

[7] T. Kobayashi, T. Ogushi, S. Haga, E. Ozaki, M. Fujii, Heat Transfer Performance of a Flexible Looped Heat Pipe Using R134a as a Working Fluid (A Proposal of a Method for Predicting the Maximum Heat Transfer Rate of FLHP), Transactions of the Japan Society of Mechanical Engineers. B 66 (2000) 1440-1446.

[8] C. Figus, L. Ounougha, P. Bonzom, W. Supper, C. Puillet, Capillary fluid loop developments in Astrium, Appl. Therm. Eng. 23 (2003) 1085-1098.

[9] C. Figus, Y. Le Bray, S. Bories, M. Prat, Heat and mass transfer with phase change in a porous structure partially heated: continuum model and pore network simulations, Int. J. Heat Mass Transf. 42 (1999) 2557-2569.

[10] T. Kaya, J. Goldak, Numerical analysis of heat and mass transfer in the capillary structure of a loop heat pipe, Int. J. Heat Mass Transf. 49 (2006) 3211-3220.

[11] M. Prat, Pore network models for the study of transfers in the porous wick of loop heat pipes, Heat Pipe Sci. and Technol. An Int. J. 1 (2010) 129-149. 
[12] C. C. Yeh, C. N. Chen, Y. M. Chen, Heat transfer analysis of a loop heat pipe with biporous wicks, Int. J. Heat Mass Transf. 52 (2009) 4426-4434.

[13] C. Figus, Y. Le Bray, S. Bories, M. Prat, Heat Transfer in Porous Media Considering Phase Change , Capillarity and Gravity . Application to Capillary Evaporator, in: Proc. of 11th Int. Heat Transf. Conference, Kyongju, Korea, 23-28 August 1998, Vol.4, pp.393-398.

[14] C. Figus, S. Bories, M. Prat, Investigation and analysis of a porous evaporator for a capillary pumped loop, in: Proc. of the Engineering Systems and Design and Analysis Conference, ASME, 1996, Vol. 8, pp. 99-106.

[15] V. Dupont, J. L. Joly, M. Miscevic, V. Platel, Capillary pumped loop startup: effects of the wick fit on boiling incipience, J. Thermophys. Heat Transfer 17 (2003) 138-144.

[16] A. Hernández, J. I. Calvo, P. Prádanos, F. Tejerina, Pore size distributions in microporous membranes. A critical analysis of the bubble point extended method, J. of membrane sci. 112.1 (1996) 1-12.

[17] T. Allen, Particle Size Measurement, Surface Area and Pore Size Determination, fifth ed., Chapman and Hall, New York, 1997.

[18] S. V. Vershinin, Y. F. Maydanik, Hysteresis phenomena in loop heat pipes, Appl. Therm. Eng. 27 (2007) 962-968.

[19] S. V. Vershinin, Y. F. Maydanik, Investigation of pulsations of the operating temperature in a miniature loop heat pipe, Int. J. Heat Mass Transf. 50 (2007) 5232-5240.

[20] J. Ku, J. I. Rodriguez, Low Frequency High Amplitude Temperature Oscillations in Loop Heat Pipe Operation, in: Proc. of 33rd Int. Conference on Environmental Systems, Vancouver, Canada, 7-10 July 2003, SAE Paper 2003-01-2386.

[21] J. Ku, High Frequency Low Amplitude Temperature Oscillations in Loop Heat Pipe Operation, in: Proc. of 33rd Int. Conference on Environmental Systems, Vancouver, Canada, 7-10 July 2003, SAE Paper 2003-01-2387.

\section{Figure captions}

Fig. 1 Schematic of a loop heat pipe.

Fig. 2 Sketch of the liquid-vapor interface in the capillary evaporator.

Fig. 3 PTFE wicks.

Fig. 4 Image of an LHP and the thermocouple positions

Fig. 5 Evaporator and CC temperature at each radius difference $(-50,0,20,50,100 \mu \mathrm{m})$ between the evaporator casing and the wick.

Fig. 6 Start-up failure on $500 \mu \mathrm{m}$ radius difference between the evaporator casing and the wick.

Fig. 7 Evaporation heat-transfer coefficient at an evaporation heat flux from 1.5 to $1.6 \mathrm{~W} / \mathrm{cm}^{2}$ on each radius difference between the evaporator casing and the wick.

Fig. 8 SEM pictures of PTFE wicks at the outer surface (x1000).

Fig. 9 Distribution of casing superheat along the evaporator axial direction on each gap distance $(-50, \quad 0,20,50,100 \mu \mathrm{m})$ between the evaporator casing and the wick.

Fig. 10 Temperature of LHP in each component and pressure difference of the evaporator on each fluid inventory with ethanol at heat loads from 38 to $40 \mathrm{~W}$.

Fig. 11 Evaporation heat-transfer coefficients on each fluid inventory at evaporation heat flux from 3.2 to $3.5 \mathrm{~W} / \mathrm{cm}^{2}$.

Fig. 12 Temperature distribution of the condenser on each fluid inventory.

Fig. 13 Evaporator temperature and pressure difference of the evaporator on ethanol, acetone and R134a.

Fig. 14 Evaporation heat-transfer coefficient and evaporation ratio to heat loads on each working fluid with $0 \mu \mathrm{m}$ gap.

Fig. 15 Time history of temperature of the test under a stepwise heat load with $20 \mu \mathrm{m}$ gap. (The upper left figure is the scale-up at start-up.)

Fig. 16 Time history of the pressure difference of temperature of the test under a stepwise heat load with $20 \mu \mathrm{m}$ gap. (The upper left figure is the scale-up at start-up.)

Fig. 17 Estimation of liquid temperature in the wick core. 
Fig. 18 Time history of temperature of the test under a stepwise heat sink with $20 \mu \mathrm{m}$ gap.

Fig. 19 Time history of the pressure difference of the test under a stepwise heat sink with $20 \mu \mathrm{m}$ gap.

Fig. 20 Thermal resistance of the heat sink test with a $20 \mu \mathrm{m}$ gap at a heat load of $30 \mathrm{~W}$.

\section{Tables}

Table 1. Radius difference on each evaporator.

\begin{tabular}{rr}
\hline \multicolumn{1}{l}{$\begin{array}{l}\text { Wick diameter } \\
{[\mathrm{mm}]}\end{array}$} & \multicolumn{2}{l}{$\begin{array}{l}\text { Radius difference to } \\
\text { evaporator casing diameter }[\mu \mathrm{m}]\end{array}$} \\
\hline \hline 10.10 & -50 \\
\hline 10.00 & 0 \\
\hline 9.96 & 20 \\
\hline 9.90 & 50 \\
\hline 9.80 & 100 \\
\hline 9.00 & 500 \\
\hline \hline
\end{tabular}

Table 3. LHP characteristics.

\begin{tabular}{lcll}
\hline \hline Evaporator Case (SUS316) & CC (SUS316) & \\
\hline Length[mm] & 50 & Length[mm] & 44 \\
O.D.[mm] & 12 & O.D. [mm] & 24 \\
I.D. [mm] & 10 & I.D. [mm] & 20 \\
Grooves & & Wick (PTFE) & 50 \\
\hline Length[mm] & 45 & Length[mm] & 10 (no gap) \\
Height[mm] & 1 & O.D. [mm] & 5 \\
Width[mm] & 1 & I.D. [mm] & \\
Number & 8 & & 1560 \\
Vapor Line (SUS304) & Liquid Line (SUS304) & 1.8 \\
\hline Length[mm] & 1150 & Length[mm] & \\
I.D. [mm] & 1.8 & I.D. [mm] & 500 \\
& & Condenser (SUS304) & \\
\hline
\end{tabular}

Table 2. Porous characteristics of PTFE.

\begin{tabular}{lr}
\hline \hline Liquid permeability $\left[\times 10^{-14} \mathrm{~m}^{2}\right]$ & 2.0 \\
\hline Mode pore radius $[\mu \mathrm{m}]$ & 1.2 \\
\hline Maximum pore radius $[\mu \mathrm{m}]$ & 1.7 \\
\hline Porosity & 0.34 \\
\hline \hline
\end{tabular}

Table 4. LHP volume and fluid inventory.

\begin{tabular}{rr}
\hline \hline$V_{c c}[\mathrm{ml}]$ & 13.0 \\
\hline$V_{\text {wick }}[\mathrm{ml}]$ & 0.6 \\
\hline$V_{\text {lines }}[\mathrm{ml}]$ & 10.8 \\
\hline & 13.0 \\
$V_{\text {charge }}[\mathrm{ml}]$ & 15.5 \\
& 18.0 \\
\hline & Ethanol \\
Material & Acetone \\
& R134a \\
\hline \hline
\end{tabular}


Table 5. Test conditions.

\begin{tabular}{lrrrrr}
\hline \hline & $\begin{array}{r}\text { Radius difference } \\
{[\mu \mathrm{m}]}\end{array}$ & Inventory ratio & Working fluid & $\begin{array}{r}\text { Heat load } \\
{[\mathrm{W}]}\end{array}$ & $\begin{array}{r}\text { Sink } \\
{\left[{ }^{\circ} \mathrm{C}\right]}\end{array}$ \\
\hline \hline No.I & Variable & 0.95 & Ethanol & Step & 30 \\
\hline No.II & 20 & Variable & Ethanol & 40 & 30 \\
\hline No.III & 0 & 1.14 & Variable & Step & 10 \\
\hline No.IV & 20 & 0.95 & Ethanol & Step & 30 \\
\hline No.V & 20 & 0.95 & Ethanol & 30 & Variable \\
\hline \hline
\end{tabular}

Table 6. Fluid performance factors at the $300 \mathrm{~K}$ saturation state.

\begin{tabular}{lrrrr}
\hline \hline & $\begin{array}{c}N_{f}=\sigma h_{\text {lat }} / v_{l} \\
{\left[\mathrm{MW} / \mathrm{m}^{2}\right]}\end{array}$ & $\begin{array}{c}d P /\left.d T\right|_{\text {sat }} \\
{[\mathrm{kPa} / \mathrm{K}]}\end{array}$ & $\begin{array}{c}h_{\text {lat }} / v_{v} \\
{\left[\mathrm{~W} \cdot \mathrm{m}^{2} / \mathrm{kg}\right]}\end{array}$ \\
\hline Ethanol & 148 & 0.503 & $1.7 \times 10^{10}$ \\
\hline Acetone & 316 & 1.41 & $5.4 \times 10^{10}$ \\
\hline R134a & 86.9 & 20.7 & $5.1 \times 10^{11}$ \\
\hline \hline
\end{tabular}




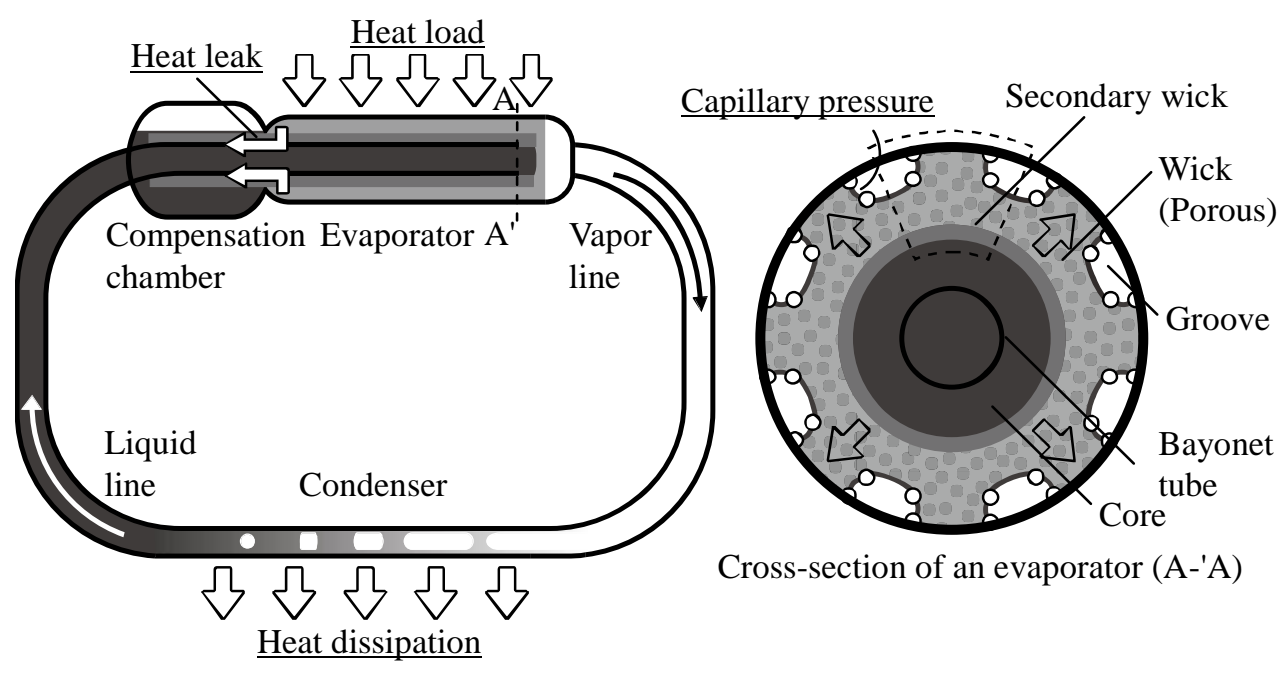


Figure2(color)

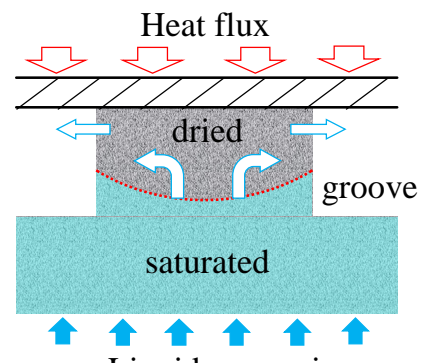

Liquid reservoir

(a) with no gap

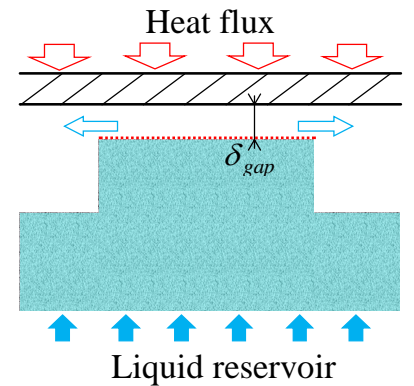

(b) with gap 


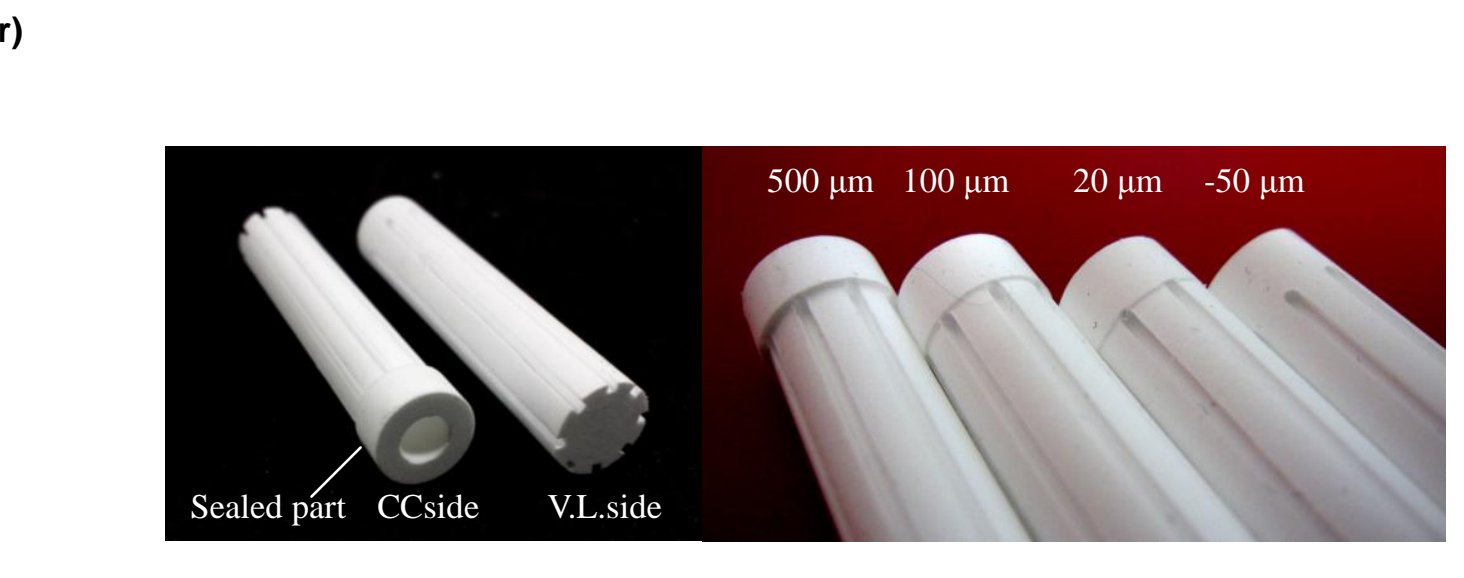

Figure3(color)

Sealed part CCside V.L.side

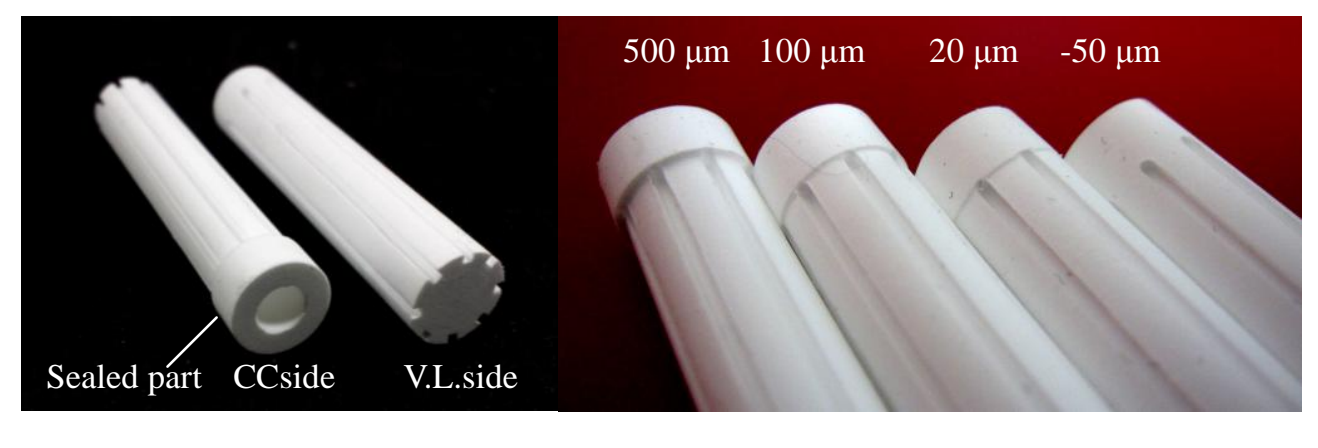

.
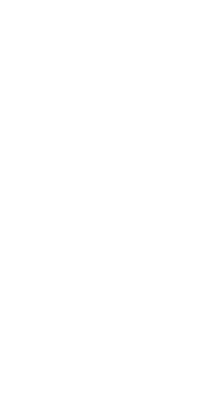


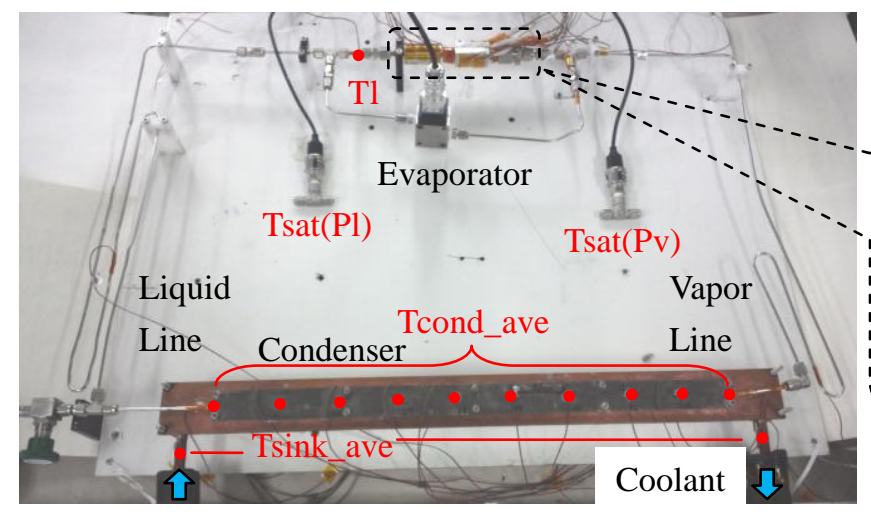

(a) Overall view

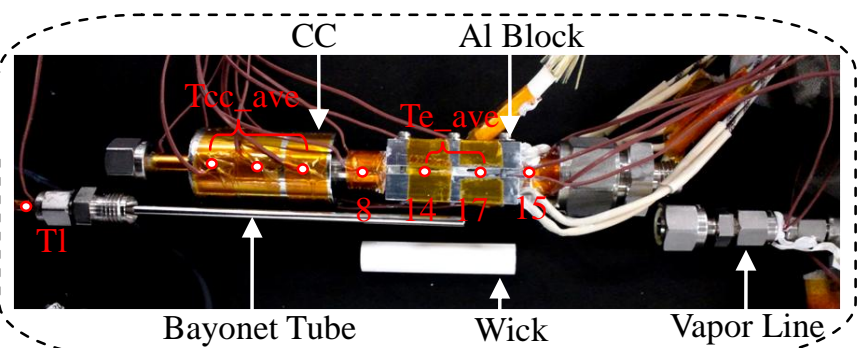

(b) Evaporator unit 


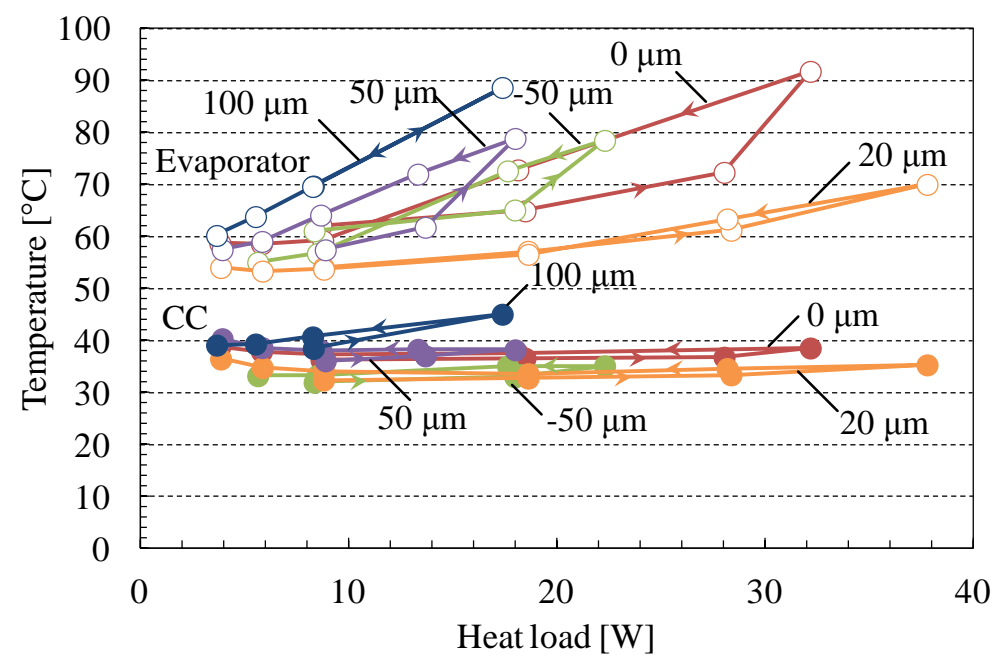




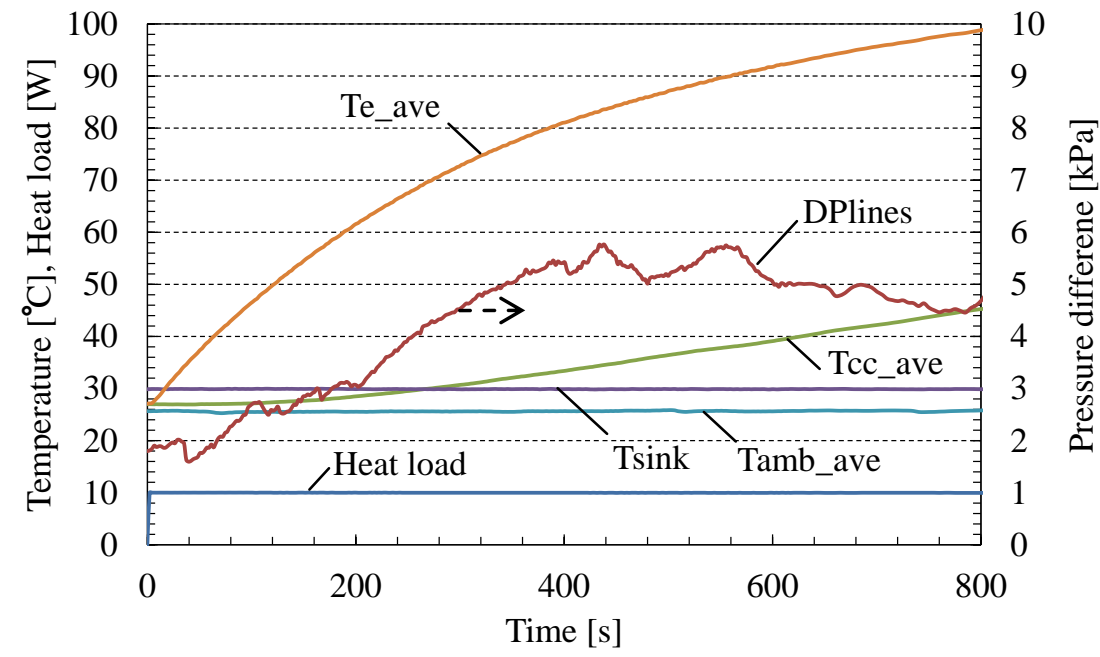


Figure7(color)

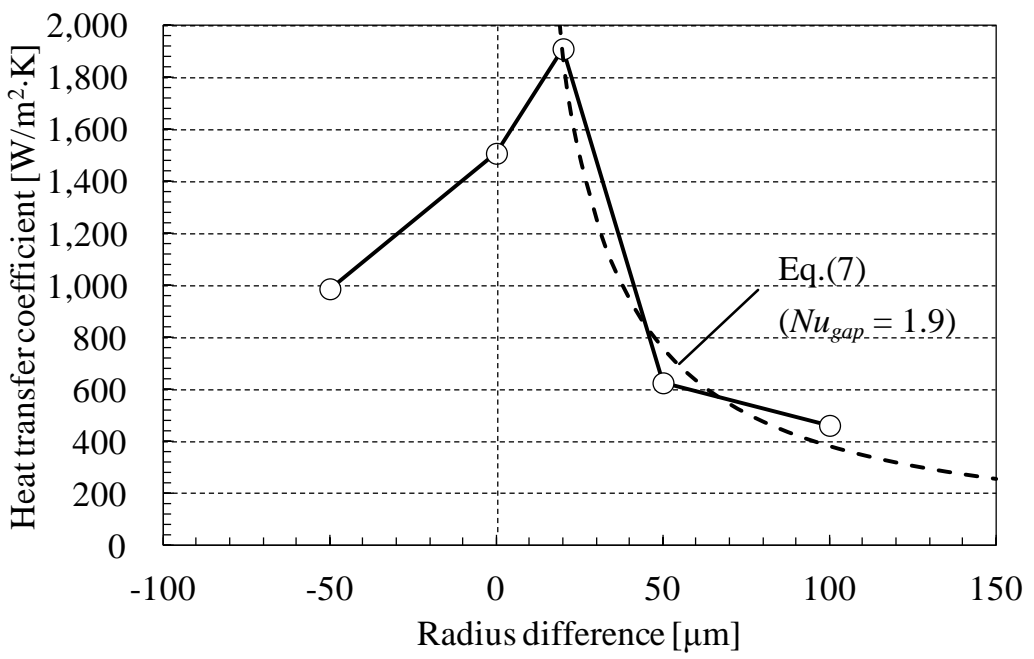




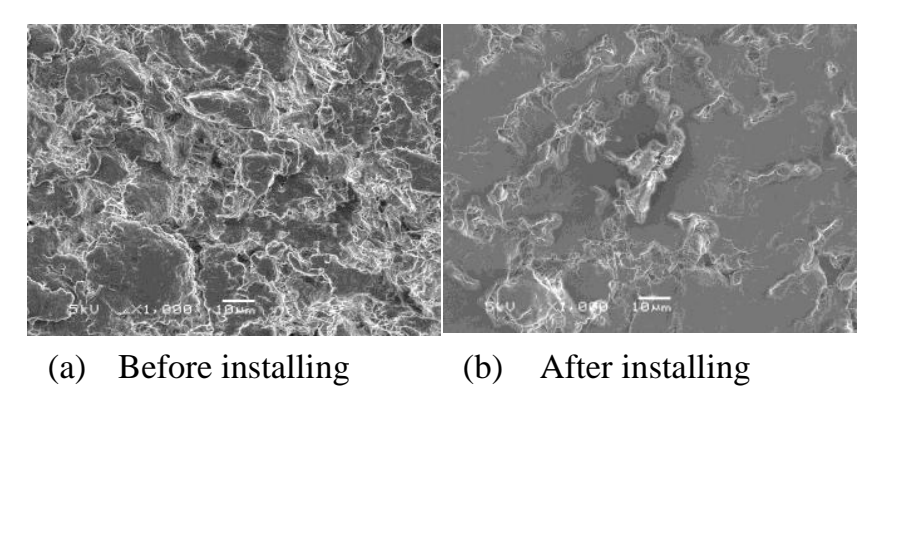

(a) Before installing

(b) After installing

Figure8(color)
(n)

(a)

(1)

(1)
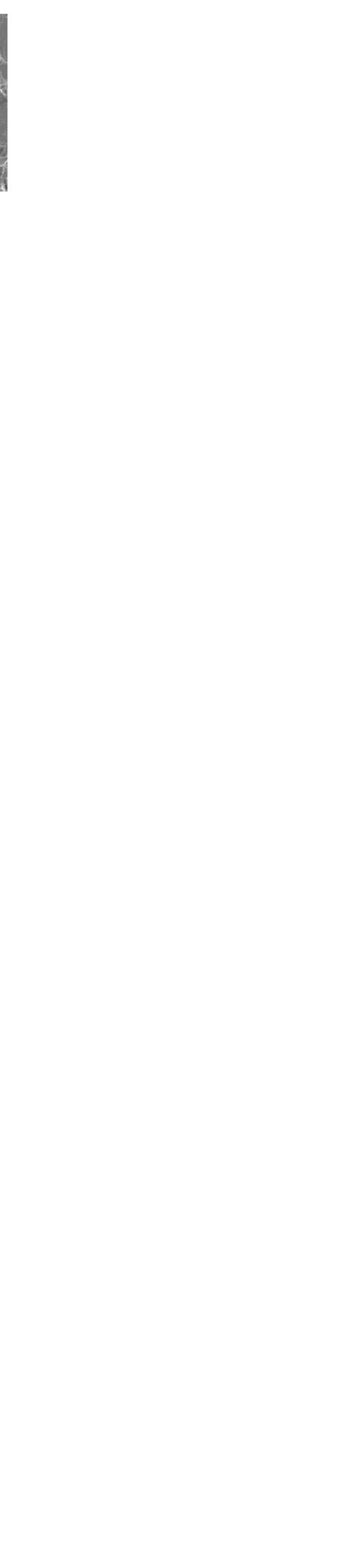


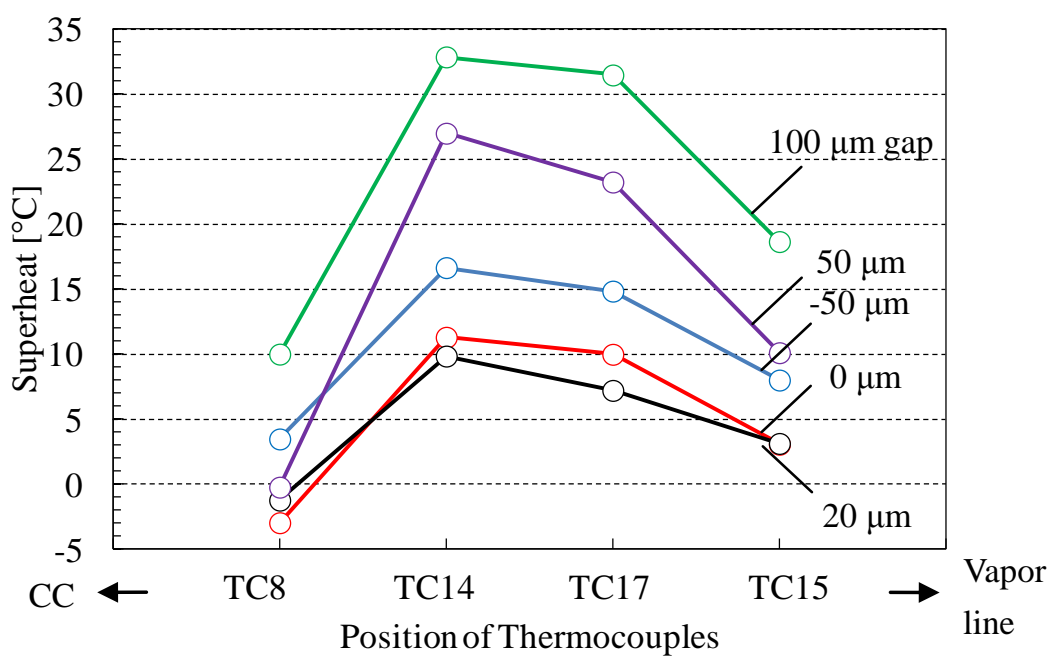




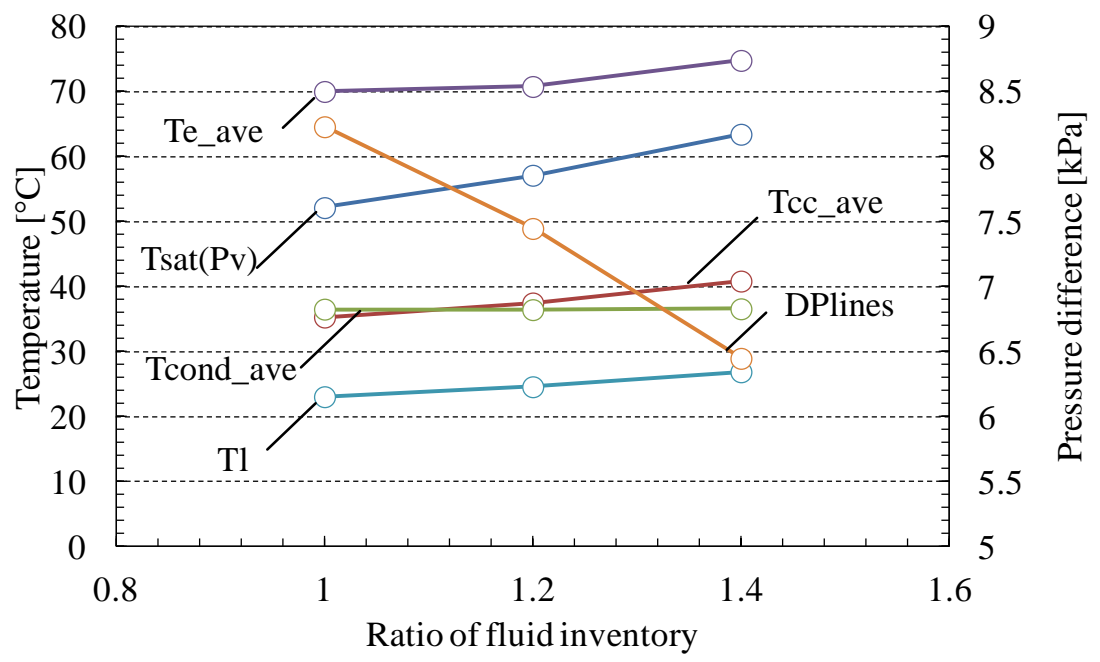

Fig. 10 Temperature of LHP each component and pressure difference of the evaporator on each fluid inventory with ethanol at heat load from 38 to $40 \mathrm{~W}$. 
Figure11(color)

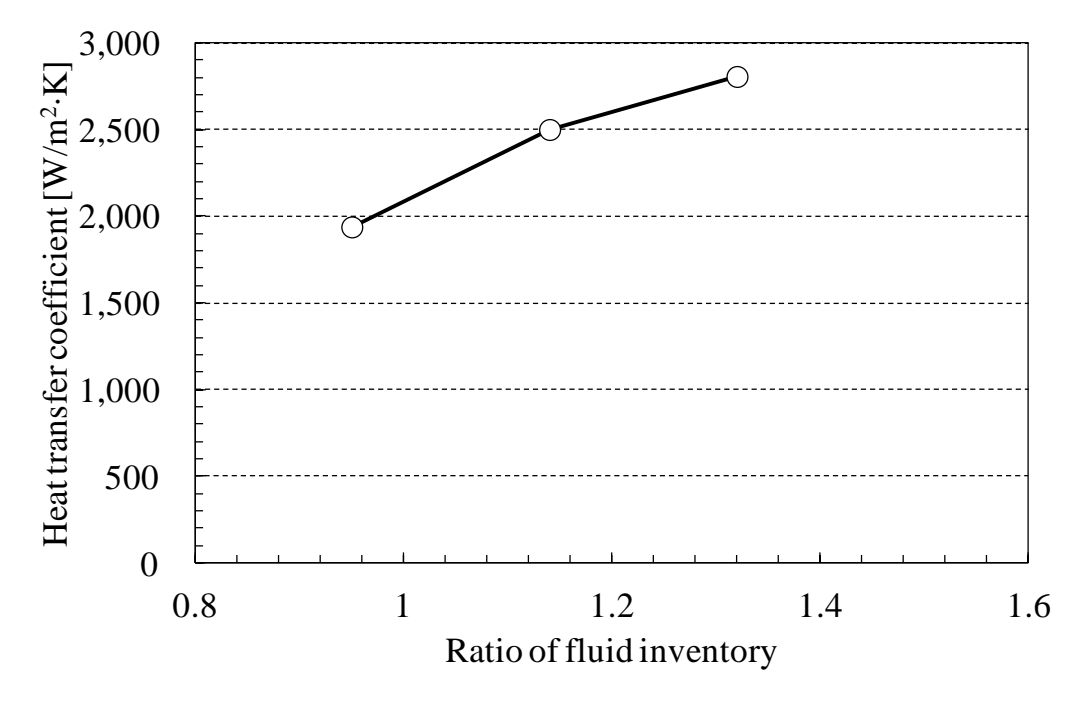

fluid inventory 


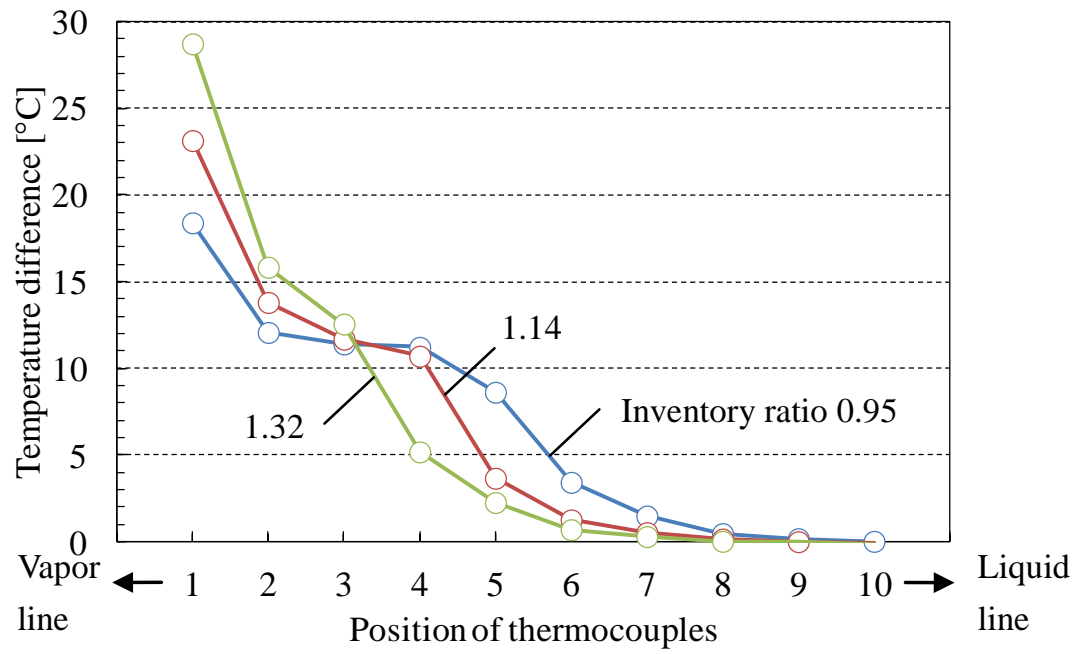




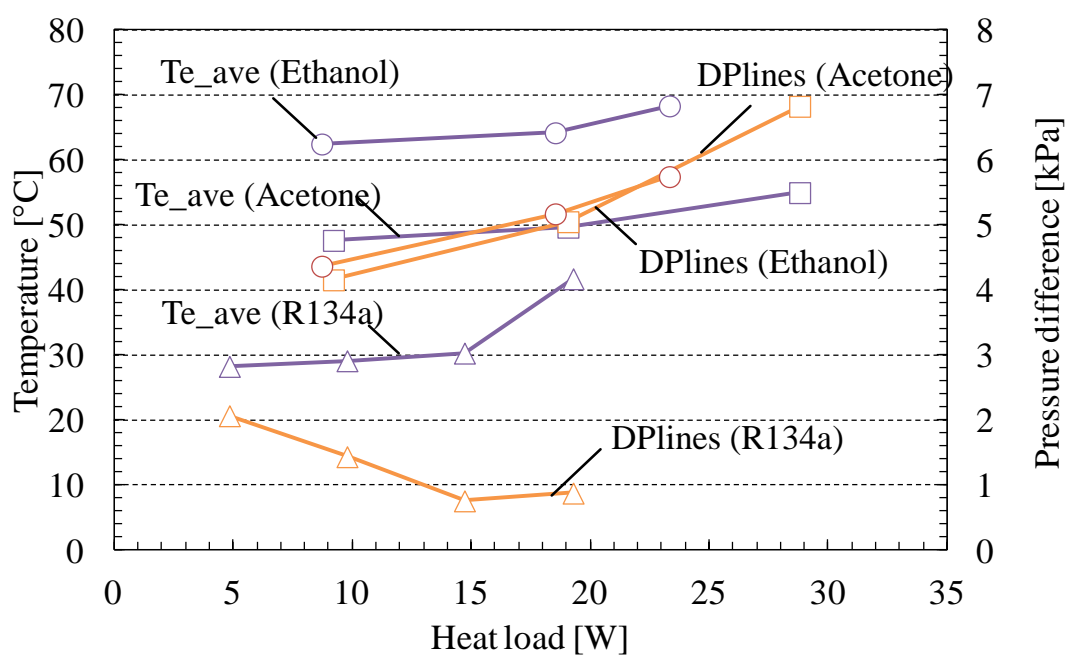

Fig. 13 Evaporator temperature and pressure difference of the evaporator on ethanol, acetone and R134a. 


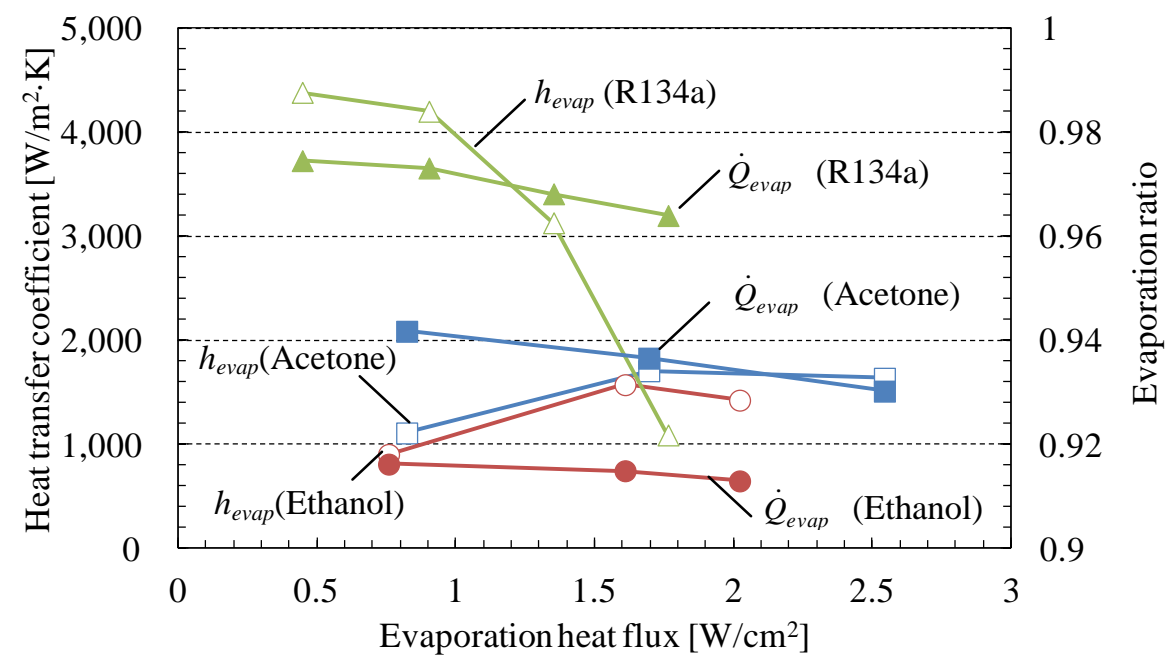




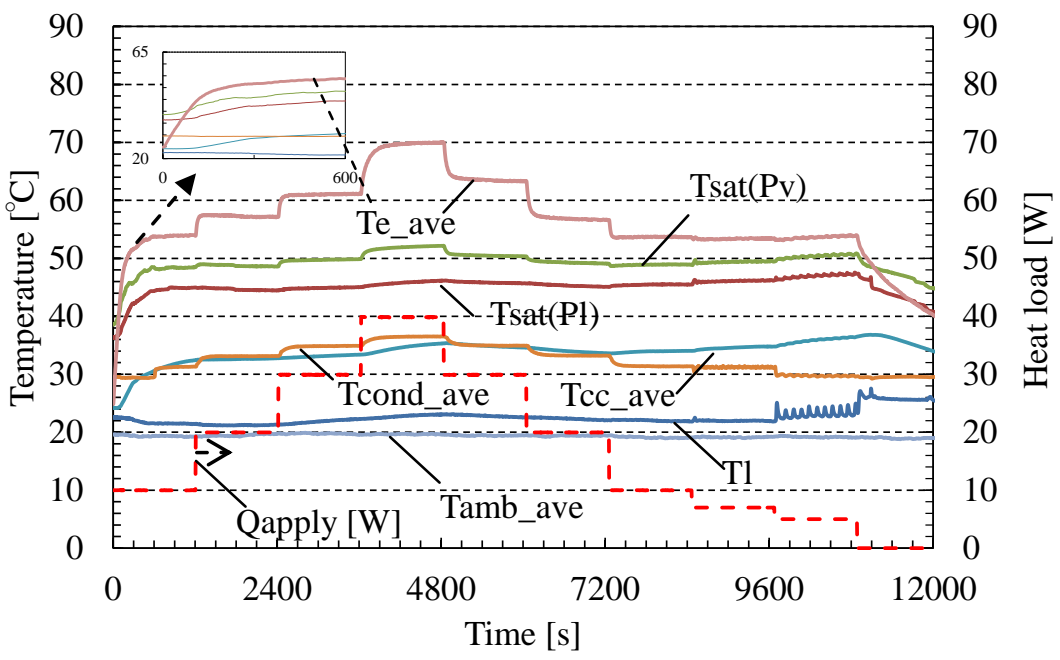




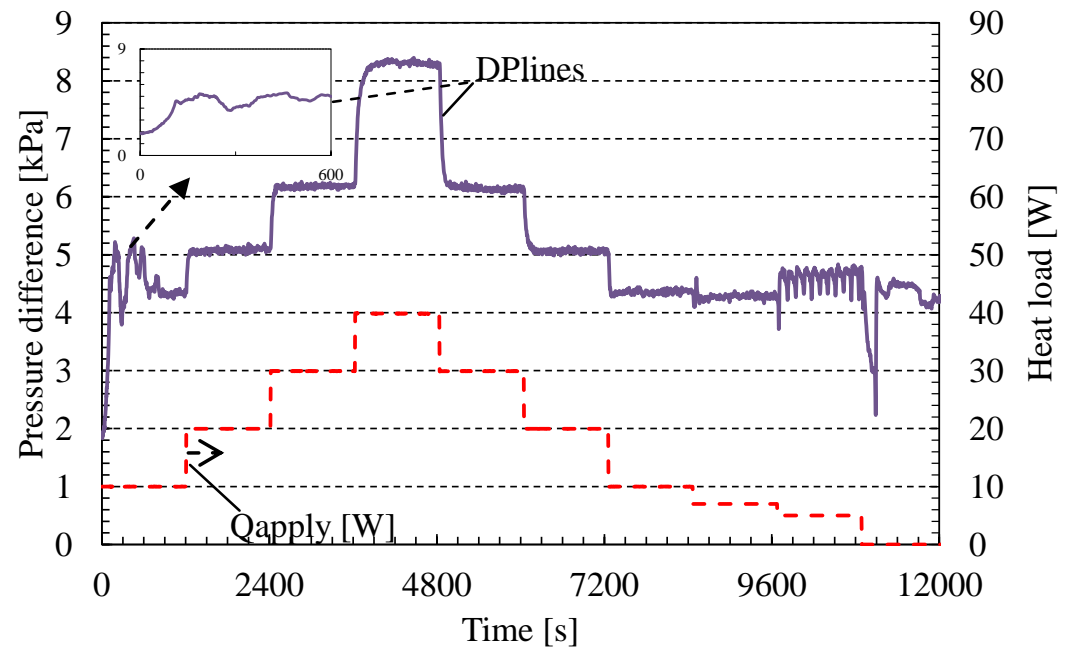




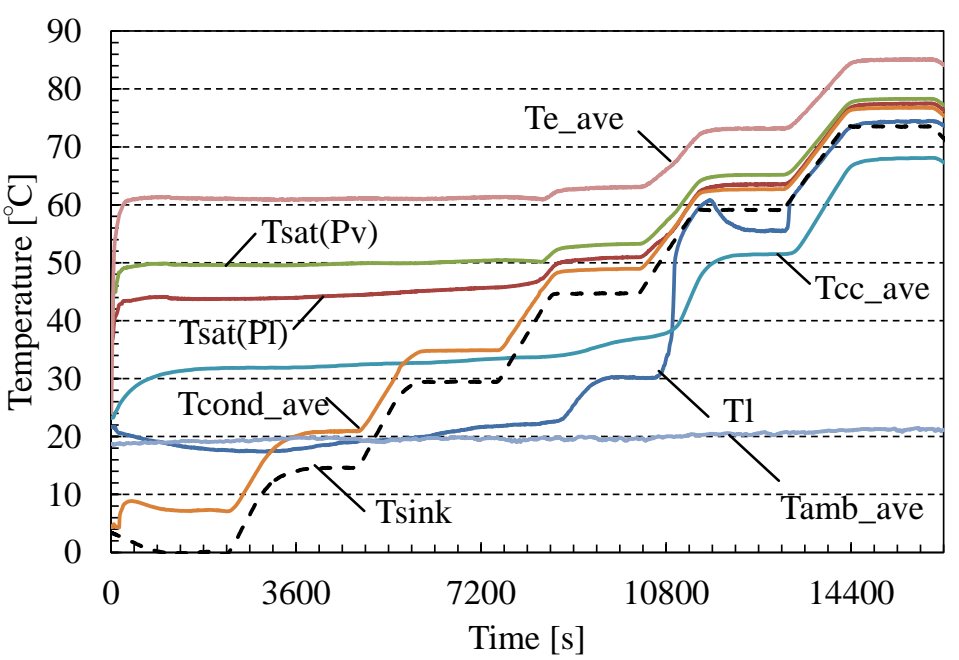




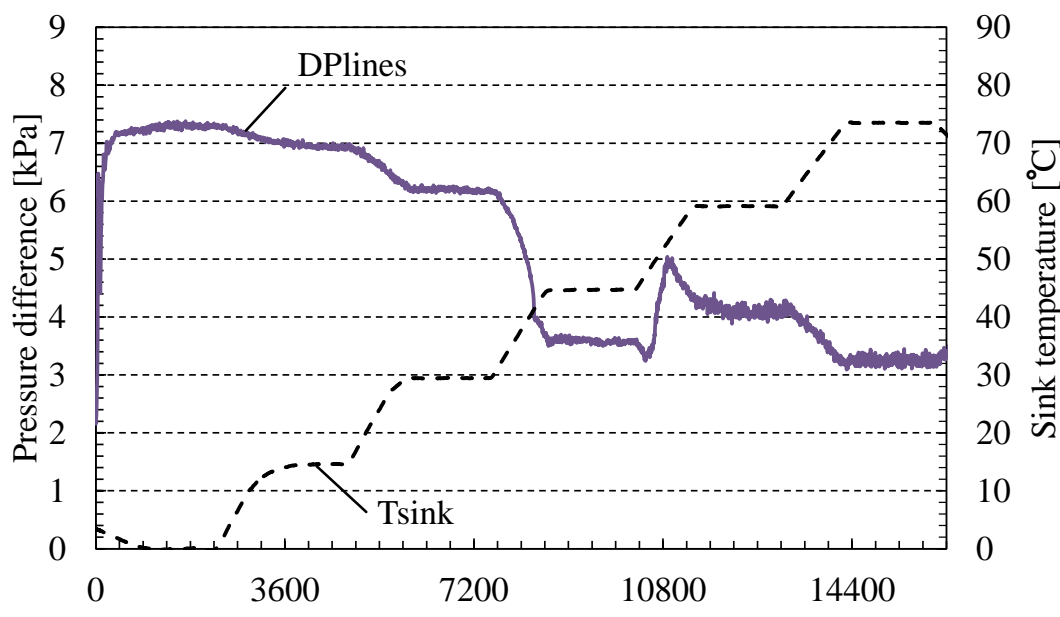

Time [s] 
Figure20(color)

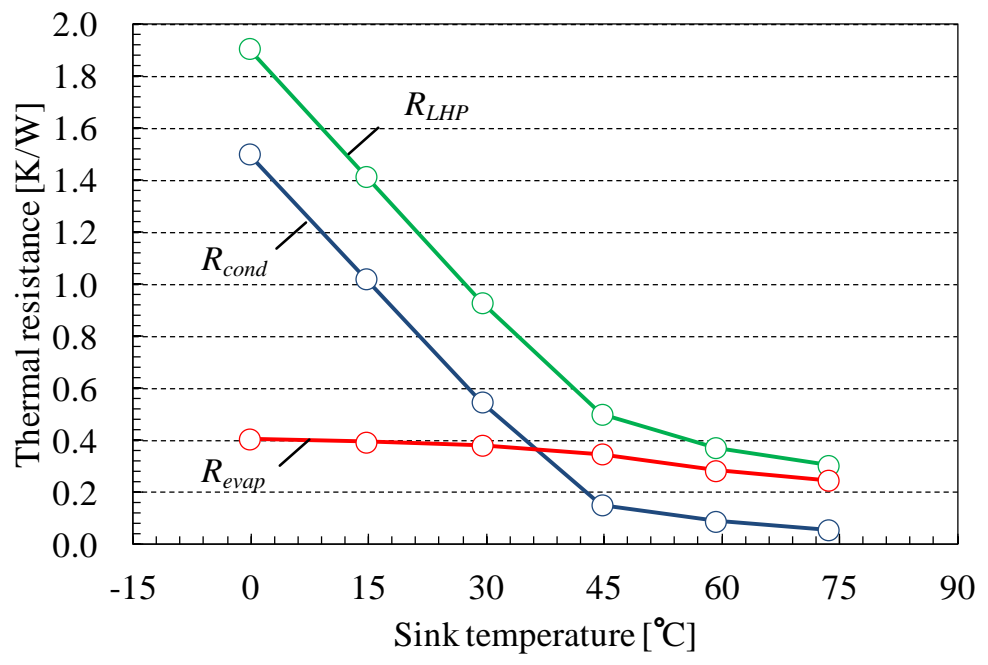

Sink temperature $\left[{ }^{\circ} \mathrm{C}\right]$ 


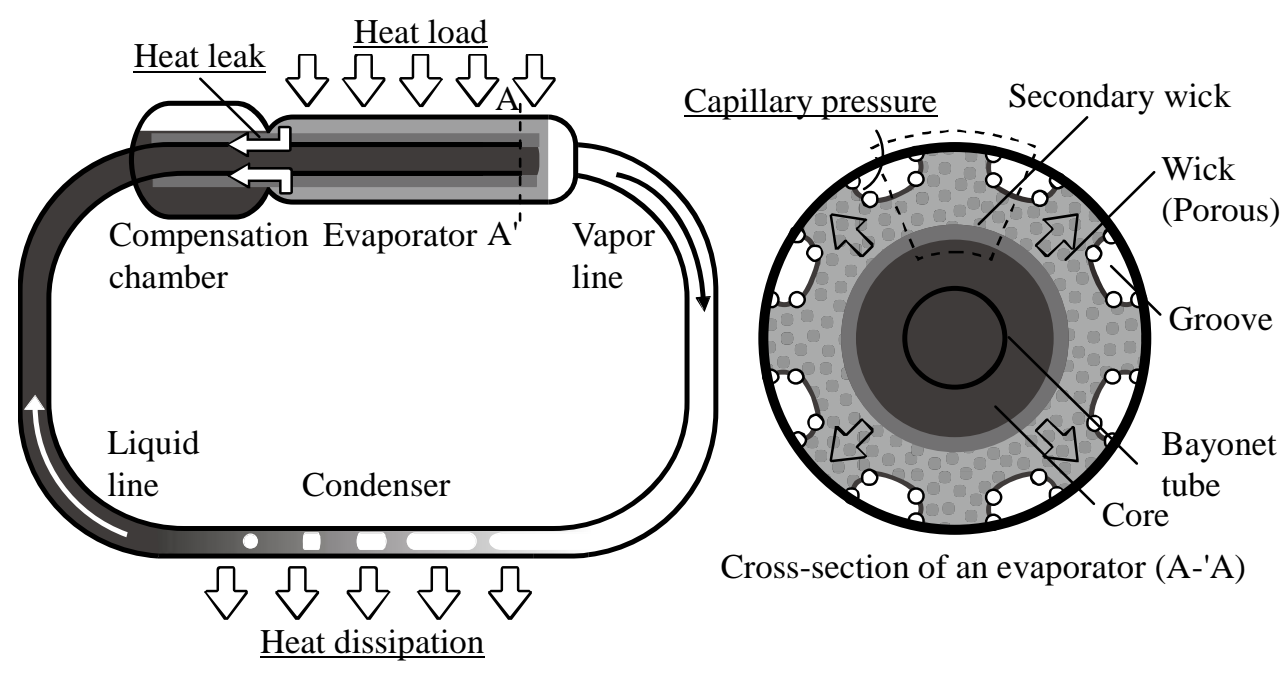


Figure2(black-and-white)

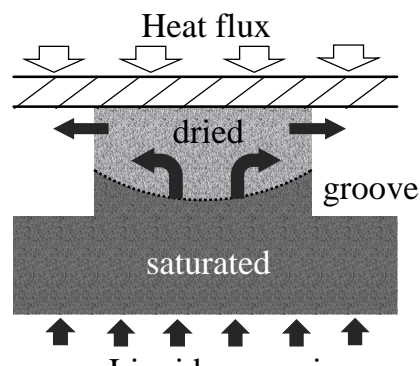

Liquid reservoir

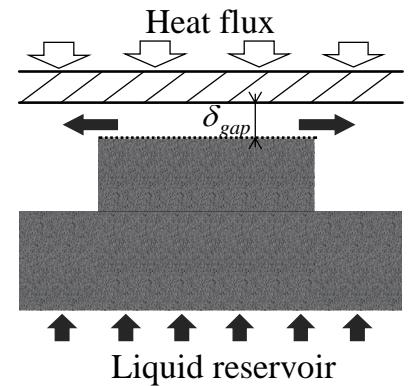
(a) with no gap
(b) with gap 
Figure3(black-and-white)
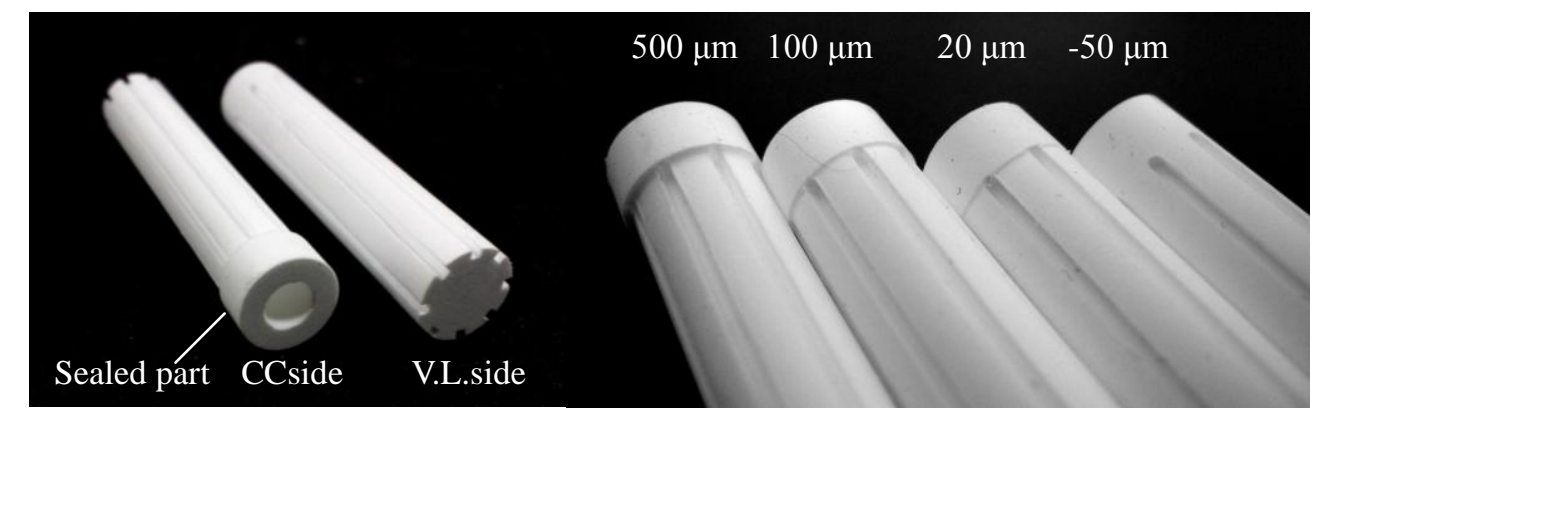

.

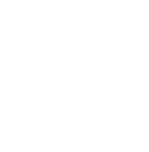
.
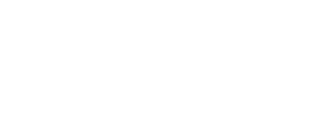
Figure4(black-and-white)

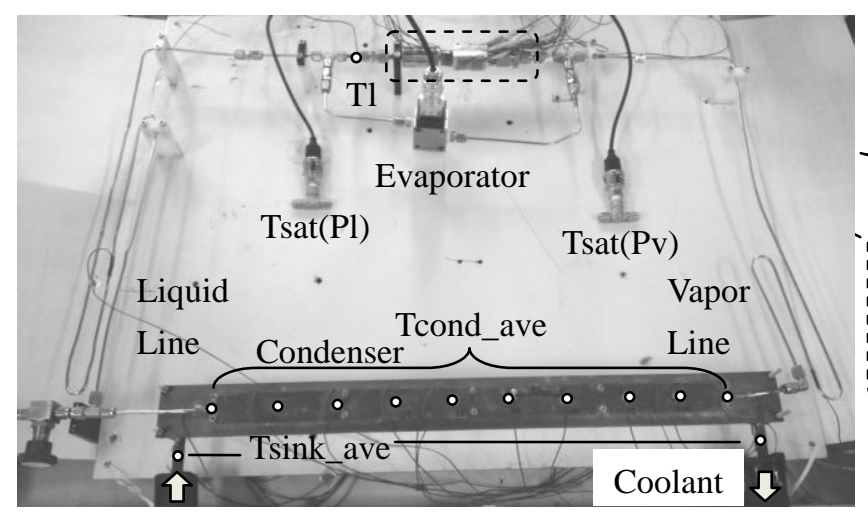

(a) Overall view

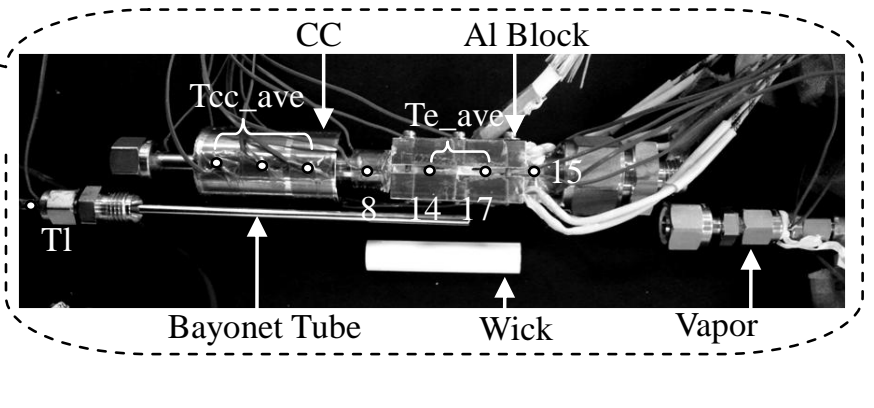

(b) Evaporator unit 
Figure5(black-and-white)

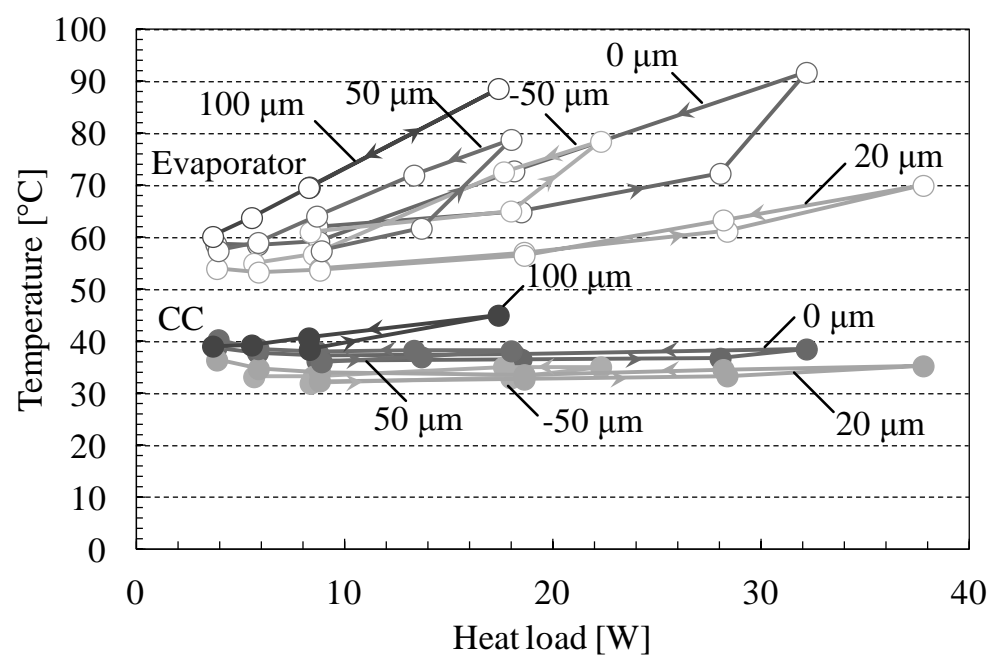




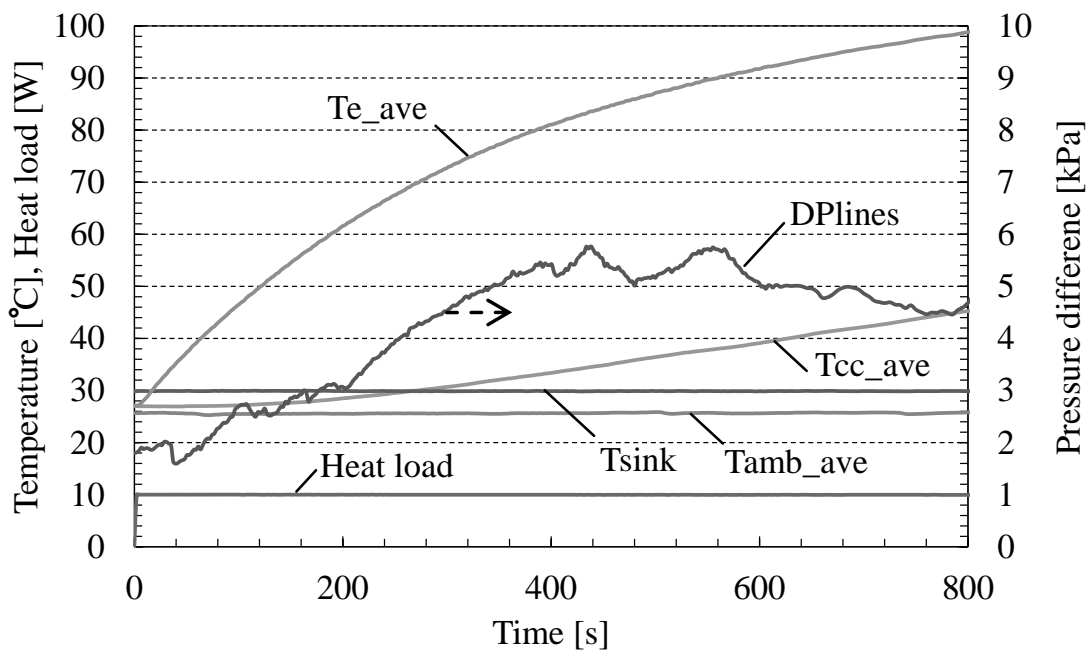


Figure7(black-and-white)

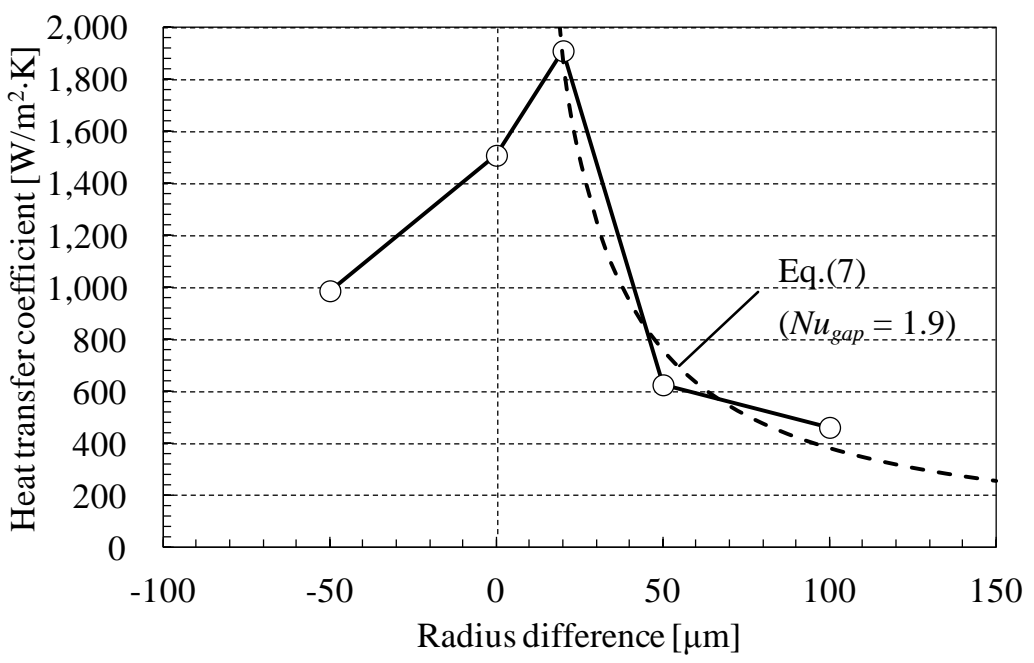




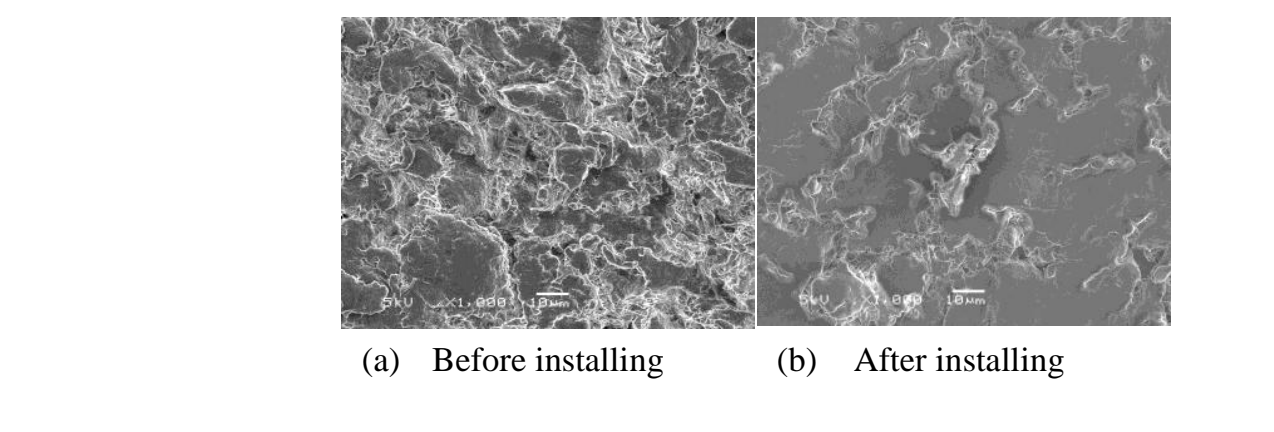

$\begin{array}{ll}\text { (a) Before installing } & \text { (b) After installing }\end{array}$

Figure8(black-and-white)

(a) Before installing

(2)

(a) Befor

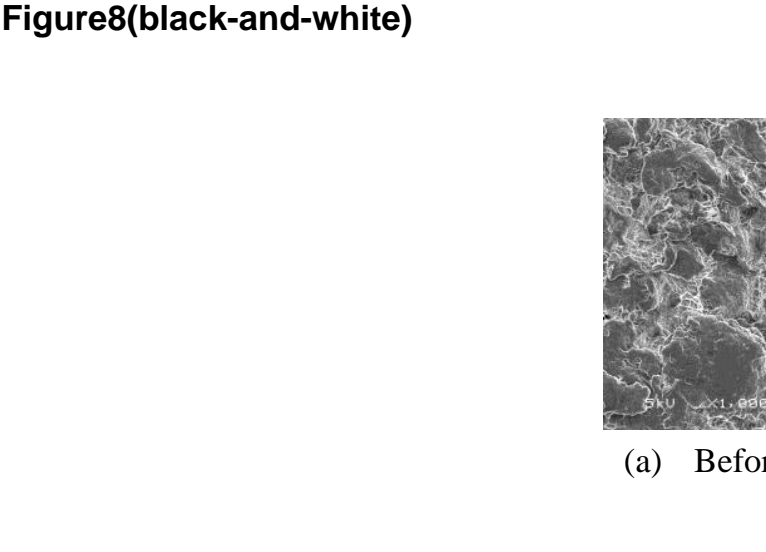

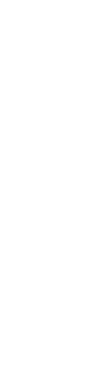

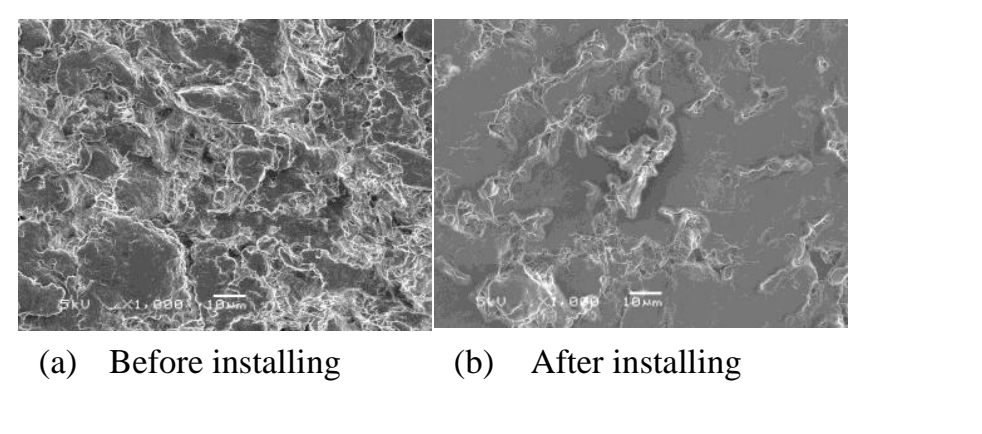

.

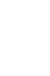

(1)

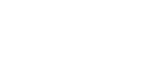

.

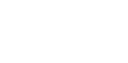

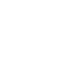

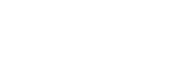

.

. 
Figure9(black-and-white)

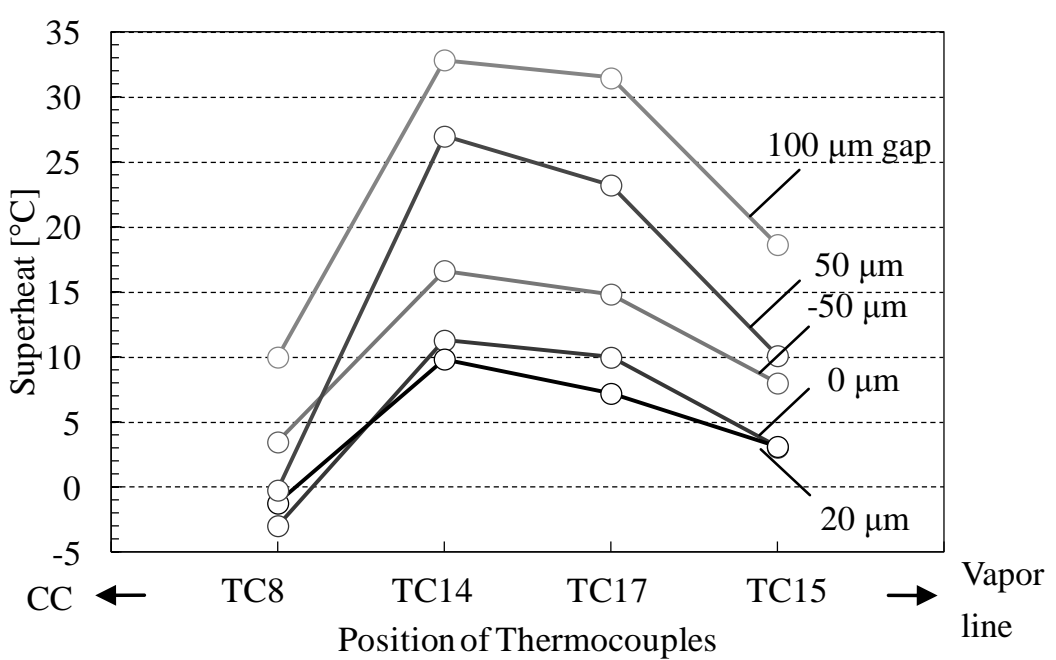




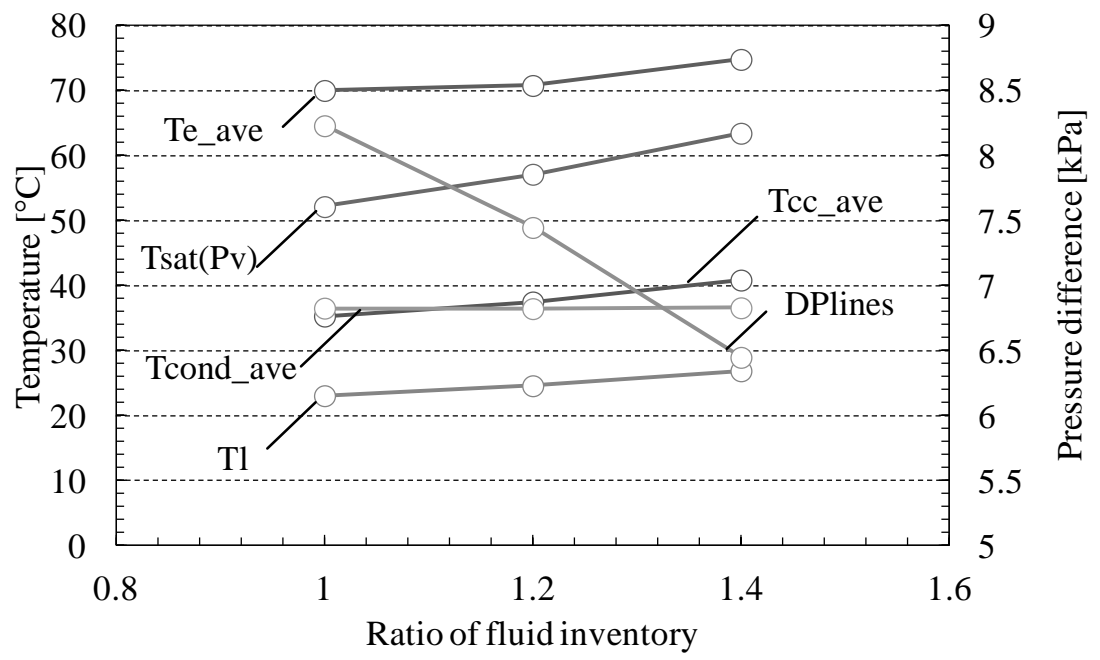

Fig. 10 Temperature of LHP each component and pressure difference of the evaporator on each fluid inventory with ethanol at heat load from 38 to $40 \mathrm{~W}$. 
Figure11(black-and-white)

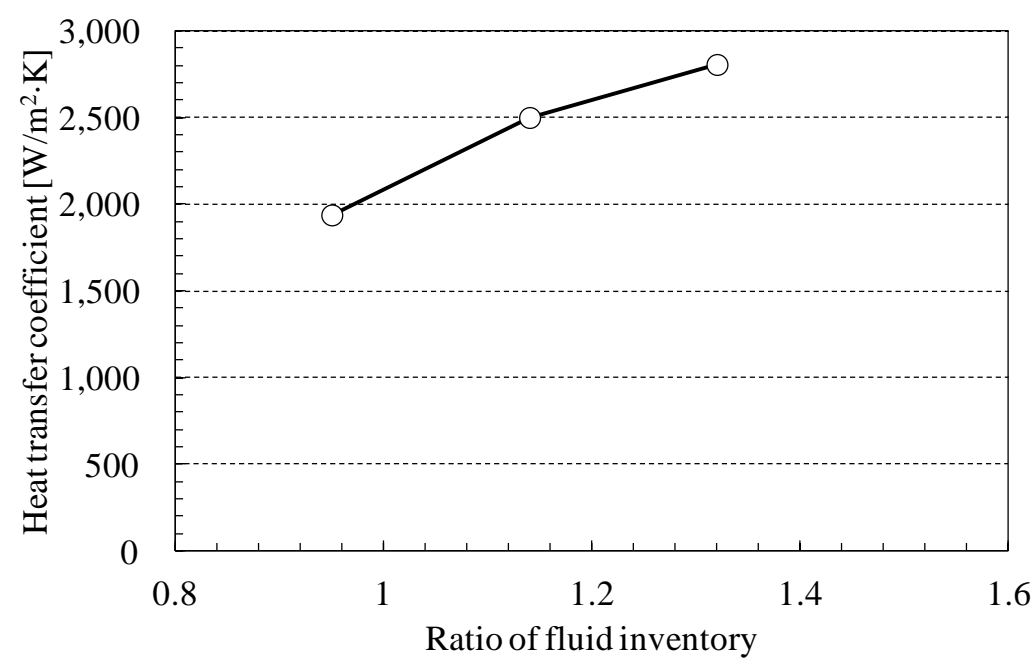

16


Figure12(black-and-white)

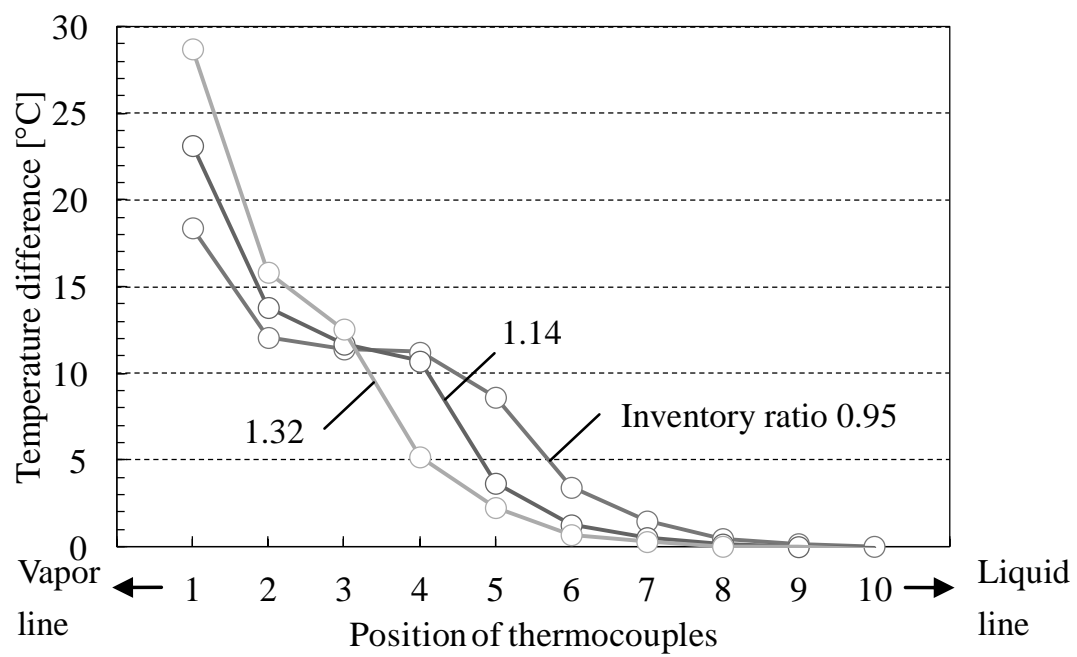




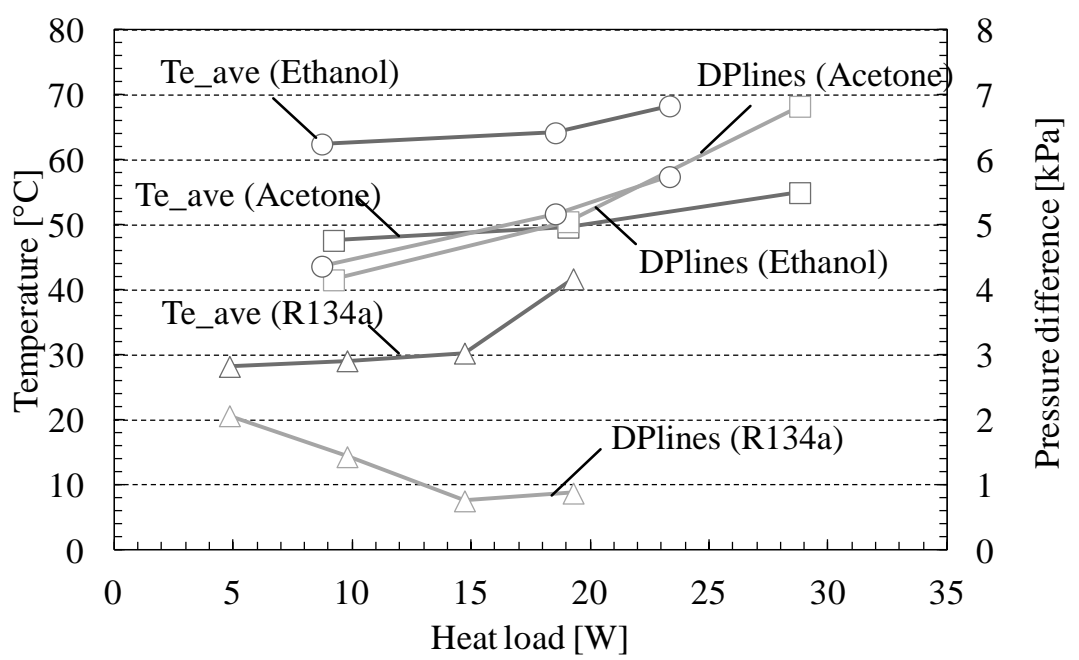

Fig. 13 Evaporator temperature and pressure difference of the evaporator on ethanol, acetone and R134a. 


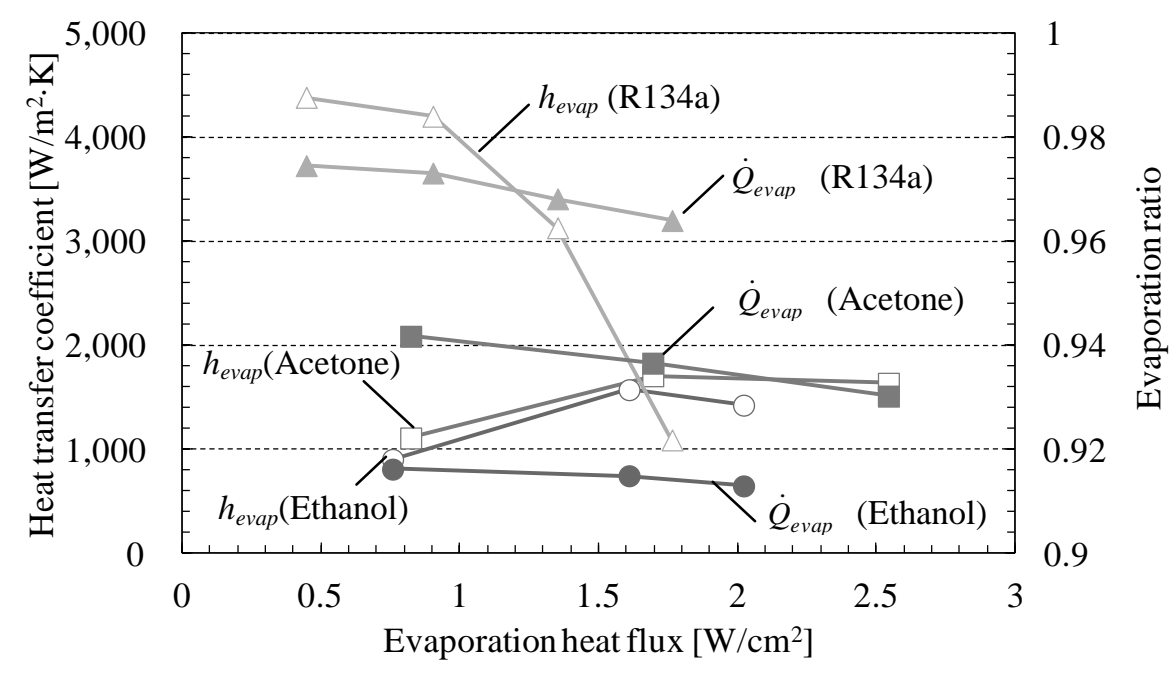




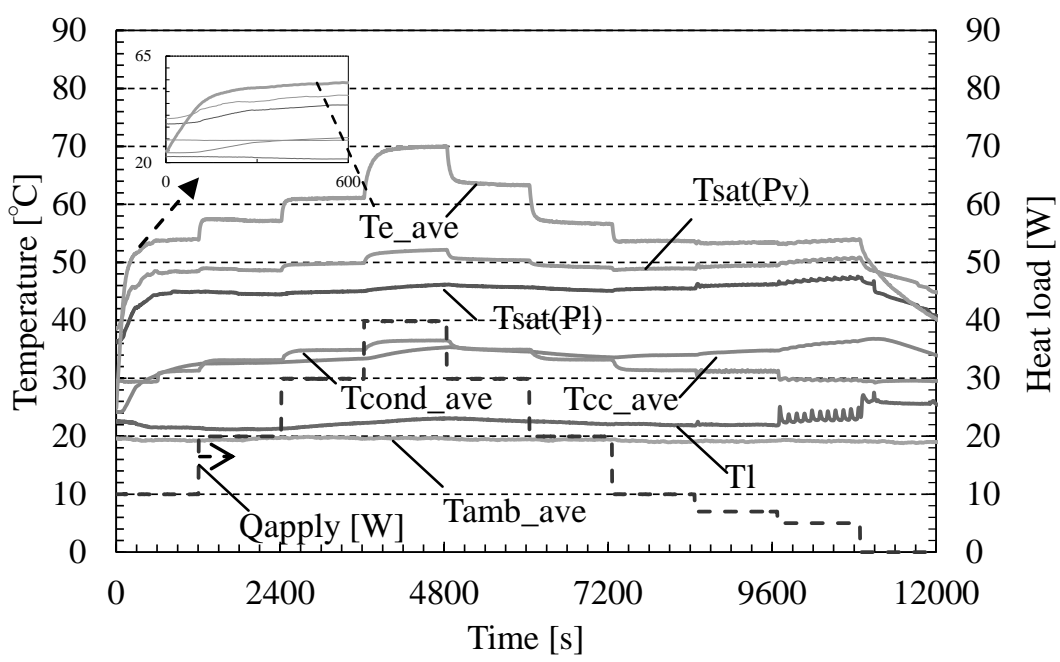


Figure16(black-and-white)

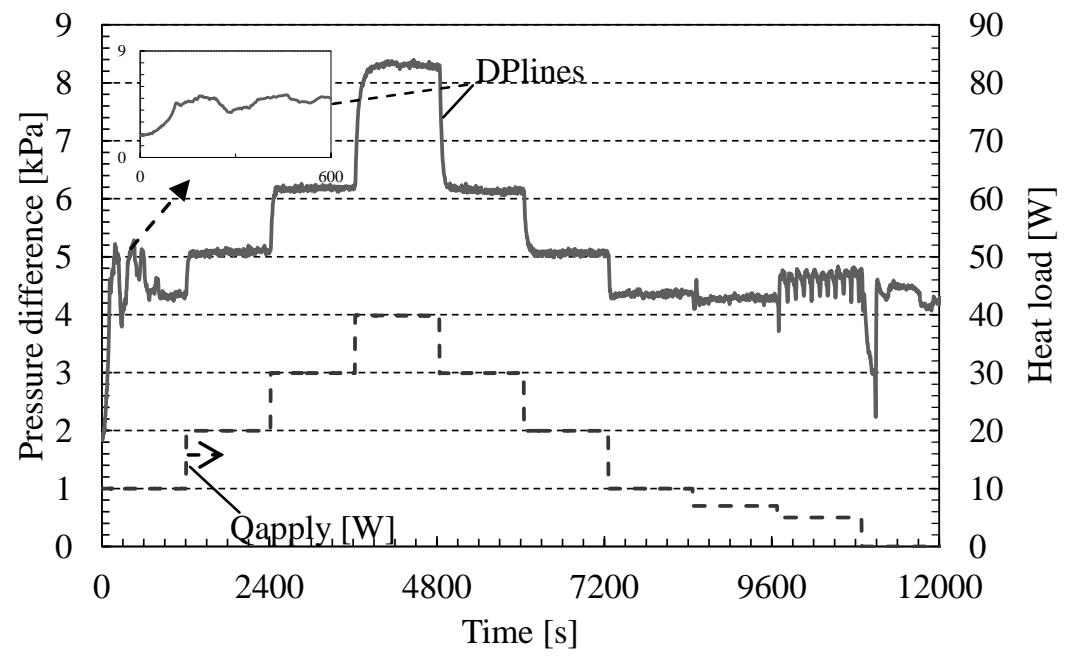




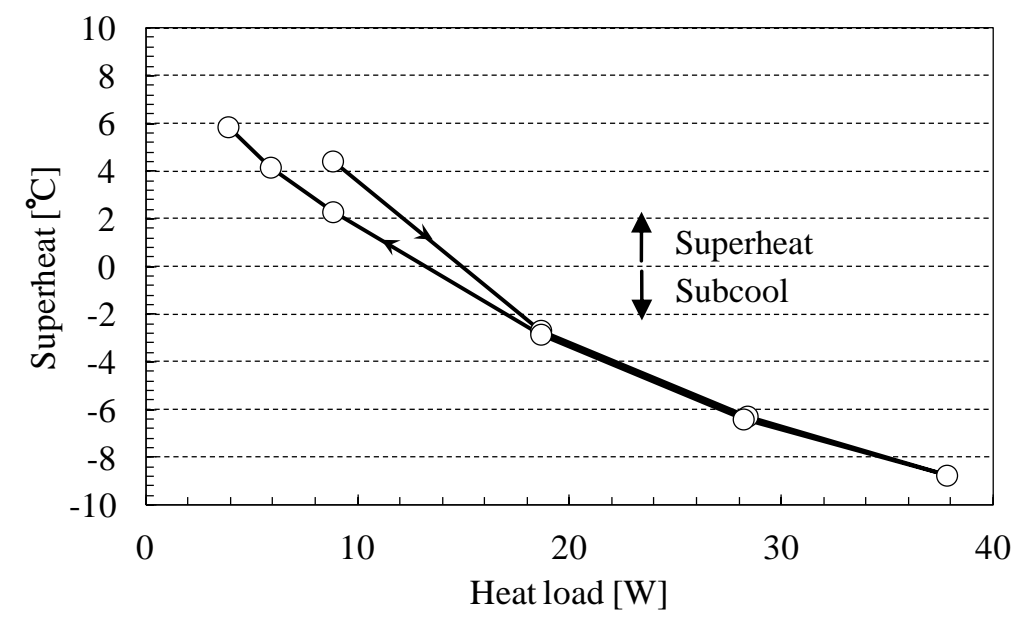




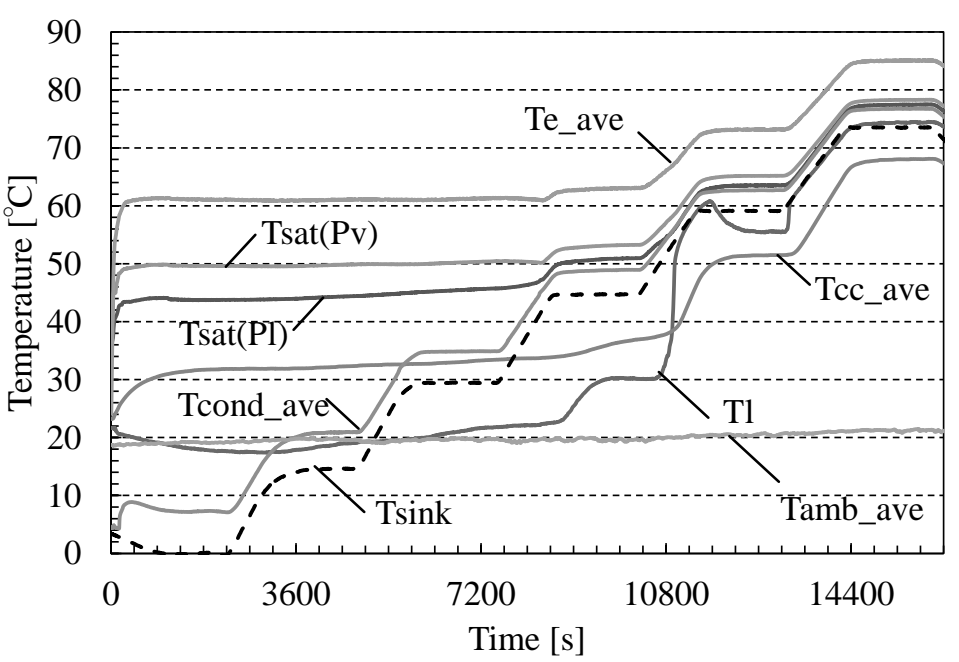


Figure19(black-and-white)

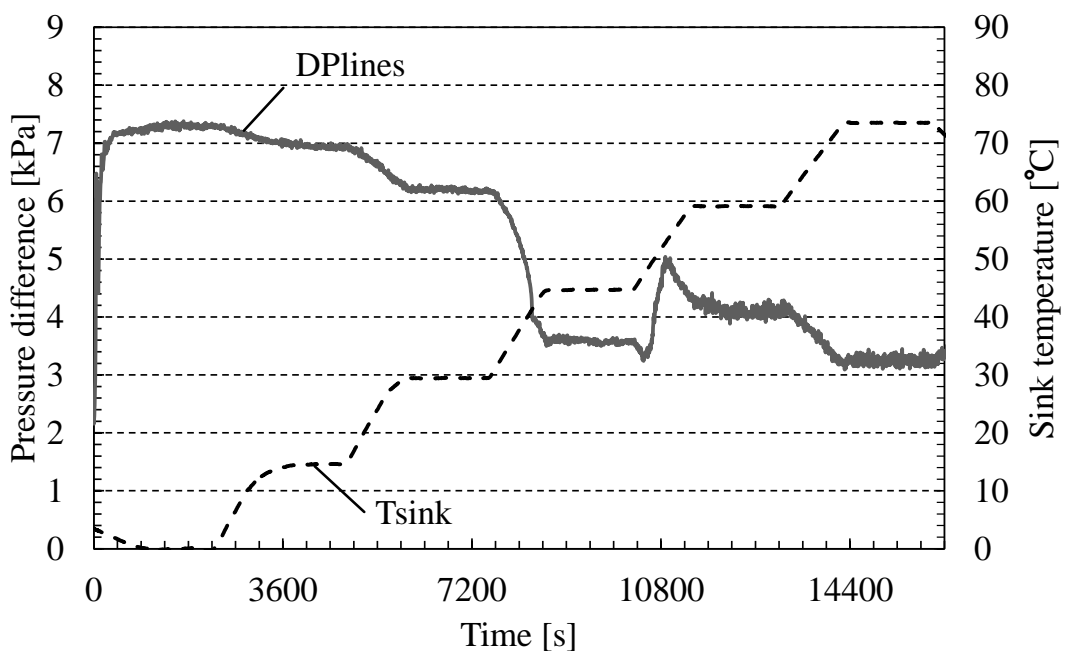


Figure20(black-and-white)

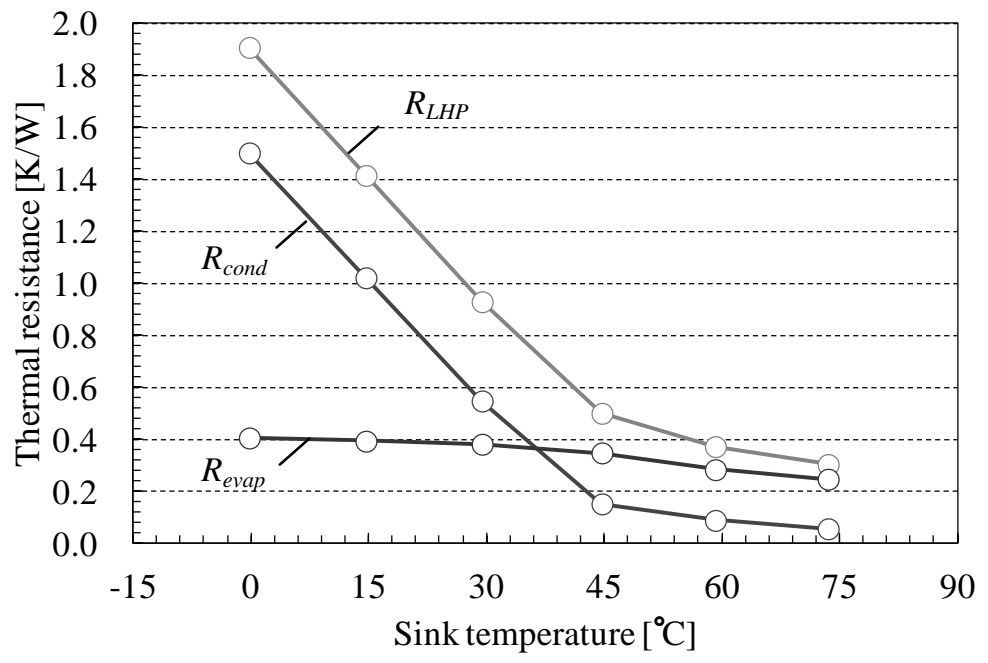

